\title{
An auroral westward flow channel (AWFC) and its relationship to field-aligned current, ring current, and plasmapause location determined using multiple spacecraft observations
}

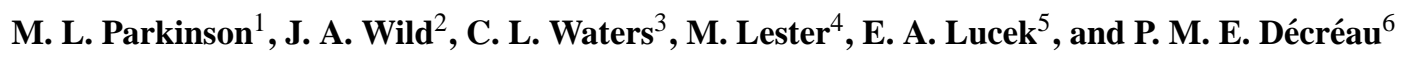 \\ ${ }^{1}$ Department of Physics, La Trobe University, Victoria 3086, Australia \\ ${ }^{2}$ Department of Communication Systems, Lancaster University, Lancaster LA1 4WA, UK \\ ${ }^{3}$ Department of Physics, University of Newcastle, New South Wales 2038, Australia \\ ${ }^{4}$ Department of Physics and Astronomy, University of Leicester, Leicester LE1 7RH, UK \\ ${ }^{5}$ Space \& Atmospheric Physics, Blackett Laboratory, Imperial College, London SW7 2BZ, UK \\ ${ }^{6}$ LPCE, CNRS et Université d'Orléans, Orléans, France
}

Received: 12 July 2006 - Revised: 30 November 2006 - Accepted: 13 December 2006 - Published: 1 February 2007

\begin{abstract}
An auroral westward flow channel (AWFC) is a latitudinally narrow channel of unstable F-region plasma with intense westward drift in the dusk-to-midnight sector ionosphere. AWFCs tend to overlap the equatorward edge of the auroral oval, and their life cycle is often synchronised to that of substorms: they commence close to substorm expansion phase onset, intensify during the expansion phase, and then decay during the recovery phase. Here we define for the first time the relationship between an AWFC, large-scale field-aligned current (FAC), the ring current, and plasmapause location. The Tasman International Geospace Environment Radar (TIGER), a Southern Hemisphere HF SuperDARN radar, observed a jet-like AWFC during $\sim 08: 35$ to 13:28 UT on 7 April 2001. The initiation of the AWFC was preceded by a band of equatorward expanding ionospheric scatter (BEES) which conveyed an intense poleward electric field through the inner plasma sheet. Unlike previous AWFCs, this event was not associated with a distinct substorm surge; rather it occurred during an interval of persistent, moderate magnetic activity characterised by AL $-200 \mathrm{nT}$. The four Cluster spacecraft had perigees within the dusk sector plasmasphere, and their trajectories were magnetically conjugate to the radar observations. The Waves of High frequency and Sounder for Probing Electron density by Relaxation (WHISPER) instruments on board Cluster were used to identify the plasmapause location. The Imager for Magnetopause-to-Aurora Global Exploration (IMAGE) EUV experiment also provided global-scale observations of the plasmapause. The Cluster fluxgate magnetometers (FGM) provided successive measurements specifying the relative location of the ring current and filamentary
\end{abstract}

Correspondence to: M. L. Parkinson

(m.parkinson@latrobe.edu.au) plasma sheet current. An analysis of Iridium spacecraft magnetometer measurements provided estimates of large-scale ionospheric FAC in relation to the AWFC evolution. Peak flows in the AWFC were located close to the peak of a Region 2 downward FAC, located just poleward of the plasmapause. DMSP satellite observations confirmed the AWFC was located equatorward of the nightside plasmasheet, sometimes associated with $\sim 10 \mathrm{keV}$ ion precipitation.

Keywords. Ionosphere (Auroral ionosphere; Electric fields and currents; Ionosphere-magnetosphere interactions)

\section{Introduction}

The circulation of plasma at high latitudes is controlled by the solar wind-magnetosphere-ionosphere interaction, and subsequent internal reconfigurations of the magnetosphere, whereas the circulation of plasma in the mid-latitude ionosphere is approximately co-rotational. However, the midlatitude ionosphere actually circulates under the influence of the tidal dynamo and prompt penetration fields (Fejer, 1997). The latter are generated when the under (over-) shielding condition develops in response to rapid changes in the magnetospheric current system (Kelley et al., 1979). When geomagnetic activity increases, prompt penetration drifts are enhanced toward the west in the evening sector ionosphere at mid-latitudes (Parkinson et al., 2001). There is often a sharp delineation between the equatorward limit of highlatitude magnetospheric convection and the approximately co-rotational mid-latitude regime. This feature is known as the flow reversal boundary (FRB) (Huang et al., 2001), and should not be confused with the convection reversal

Published by Copernicus GmbH on behalf of the European Geosciences Union. 
boundary, a feature approximately coincident with the polar cap boundary.

The FRB is indicated, and perhaps formed by, the "subauroral polarisation stream" (SAPS) (Foster and Burke, 2002). SAPS refers to a broad channel of moderate westward flow $\left(\sim 100\right.$ to $\left.400 \mathrm{~m} \mathrm{~s}^{-1}\right)$ usually associated with the development of a polarisation field across the main ionospheric trough in the dusk to post-midnight sector. Because the SAPS resides on the equatorward edge of the return sunward flow of the dawn convection cell, the FRB can be especially well defined beyond midnight. The relationship between SAPS and the ring current (RC) was investigated using CRRES spacecraft measurements of electric and magnetic fields (Wygant et al., 1998; Burke et al., 1998).

Galperin et al. (1973) originally discovered polarisation jets (PJs), very narrow channels $\left(<1\right.$ to $2^{\circ} \Lambda$ ) of intense westward plasma flow $\left(500 \mathrm{~m} \mathrm{~s}^{-1}\right.$ to $\left.>4 \mathrm{~km} \mathrm{~s}^{-1}\right)$ forming in proximity to SAPS. PJs have been referred to by various terms including sub-auroral ions drifts (SAID) (Spiro et al., 1979), substorm-associated radar auroral surges (SARAS) (Freeman et al., 1992; Shand et al., 1998), sub-auroral electric fields (SAEF) (Karlsson et al., 1998), and auroral westward flow channels (AWFC) (Parkinson et al., 2003a). The diverse SAPS nomenclature has arisen from observations of different aspects of the same phenomena, and the important distinctions need to be reconciled.

AWFCs may represent the poleward most subset of $\mathrm{PJ} / \mathrm{SAIDs}$ which emerge at substorm onset. In terms of electric fields, AWFCs are the strongest signature of substorms (Parkinson et al., 2006). Parkinson et al. (2003a) suggested AWFCs feed the development of the SAPS. Defining the relationship between AWFCs and the main population of PJ/SAIDs and SAPS occurring further equatorward will require a latitudinal chain of sub-auroral radars making continuous observations throughout the entire substorm cycle. Defining this morphology is important because of its implications for the development of field-aligned current (FAC) and polarisation fields within the inner magnetosphere, and energisation of the radiation belts and the $\mathrm{RC}$ during major storms.

Parkinson et al. (2003a) identified AWFCs with the Tasman International Geospace Environment Radar (TIGER) $\left(147.2^{\circ} \mathrm{E}, 43.4^{\circ} \mathrm{S}\right.$ Geodetic; $-55^{\circ}$ magnetic) (Dyson and Devlin, 2000; Dyson et al., 2003, 2005) an element of the Super Dual Auroral Radar Network (SuperDARN). A description of SuperDARN radar design and operation has been given by Greenwald et al. (1985, 1995). In this study, we establish the relationship between AWFC evolution and the location of large-scale ionospheric FAC, the RC, and plasmapause location. The large-scale FAC was provided by an analysis of Iridium satellite measurements (Waters et al., 2001). The relative location of the RC and plasmapause were provided by a magnetically conjugate perigee crossing of the nightside plasmasphere by the four Cluster satellites (Escoubet et al., 1997). Observations made using the Imager for Magnetopause-to-Aurora Global Exploration (IMAGE) spacecraft (Mende et al., 2000a, b) were also used to identify the relationship between the AWFC and plasmapause morphology. The polar orbiting Defence Meteorological Satellite Program (DMSP) satellites also placed the AWFC in the context of auroral oval boundaries.

\section{Observations and results}

In this study, we concentrate on the analysis of observations made by ground-based magnetometers, a suite of spacecraft including the Cluster satellites, IMAGE, and the Iridium ${ }^{\circledR}$ constellation, and the TIGER Tasmania radar during 06:0014:00 UT on 7 April 2001. The second TIGER New Zealand radar did not commence operations until late 2004.

The radar measurements were mapped to altitude adjusted corrected geomagnetic (AACGM) coordinates (Baker and Wing, 1989) using the standard algorithm which assumes rectilinear radio-wave propagation to F-region backscatter locations at a virtual height of $300 \mathrm{~km}$. Although the true mapping from group delay to ground range will change with propagation conditions, the standard mapping procedure is usually considered accurate to $<0.5^{\circ}$ for half-hop ionospheric scatter (Yeoman et al., 2001).

The magnetic coordinates of the low-altitude satellite measurements were calculated using the AACGM algorithm, but the high-altitude Cluster measurements were mapped using the Tsyganenko 96 (T96) model (Tsyganenko, 1995; Tsyganenko and Stern, 1996). Hence the problem of coordinate registration between these diverse data sets was minimised.

\subsection{Solar wind and geomagnetic conditions}

The Advanced Composition Explorer (ACE) spacecraft was located upstream in the solar wind during 7 April 2001. ACE magnetometer (Smith et al., 1998) observations of the interplanetary magnetic field (IMF) are available online and they revealed $B_{z}$ had several excursions to values more negative than $-6 \mathrm{nT}$ during 00:00 to 07:00 UT, then the $B_{x}, B_{y}$ and $B_{z}$ components were predominately $\sim+4 \mathrm{nT},-2 \mathrm{nT}$ and $-2 \mathrm{nT}$, respectively, during 07:00 to 14:00 UT. However, $B_{z}$ had several excursions to $-4 \mathrm{nT}$. ACE solar wind electron proton alpha monitor (SWEPAM) (McComas et al., 1998) observations showed the solar wind speed was $\sim 440 \mathrm{~m} \mathrm{~s}^{-1}$ and the dynamic pressure $\sim 1 \mathrm{nPa}$. However, there was significant structure in the dynamic pressure during 07:58 to 08:33 UT (this time interval is shaded in Fig. 1), including a distinct dynamic pressure pulse (DPP) from $\sim 0.7$ to $2.1 \mathrm{nPa}$ arriving during 08:10 to 08:16 UT. The arrival time of the DPP at the magnetopause was calculated using a lag of $58.9 \mathrm{~min}$ estimated using the method of Khan and Cowley (1999).

Figure 1a shows key geomagnetic indices for 7 April. The $\mathrm{AL}$ index revealed the occurrence of a $-551 \mathrm{nT}$ substorm (1) during 00:00 to 03:00 UT, followed by another $-529 \mathrm{nT}$ 


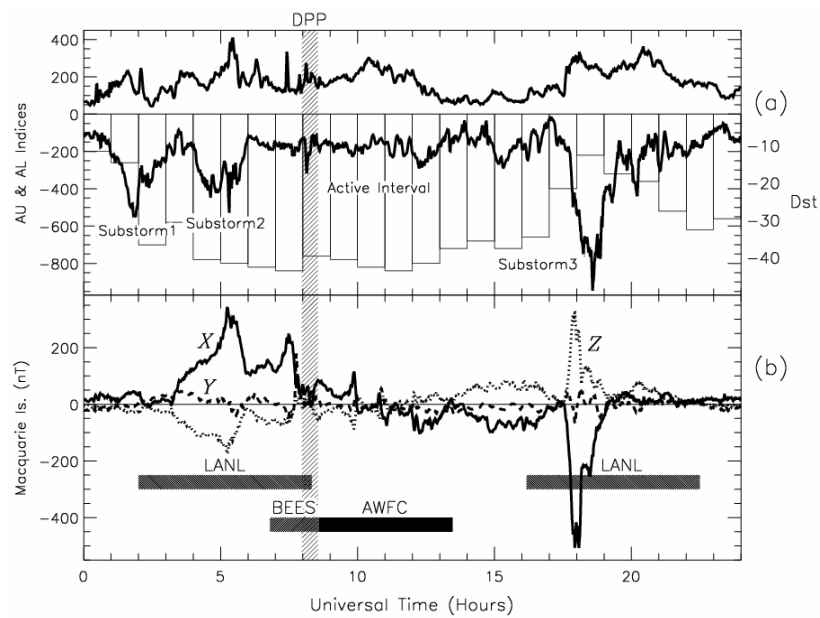

Fig. 1. (a) The AU and AL geomagnetic indices (bold curves) measured during 7 April 2001. These indices are a measure of eastward and westward current flow in the auroral ionosphere, respectively. The $D_{s t}$ index has been superimposed in the form of a faint bar chart. (b) Perturbations of the geomagnetic $X$ (solid curve), $Y$ (dashed curve), and $Z$ (dotted curve) components measured by the magnetometer located on Macquarie Island (see Fig. 8). Two horizontal bars indicate approximate time intervals when the LANL satellites observed rapid decreases and increases in energetic particle flux at geosynchronous orbit. Horizontal bars also indicate when TIGER observed a band of equatorward expanding scatter (BEES), and an auroral westward flow channel (AWFC).

substorm (2) during 03:00-06:00 UT. The recovery of the second substorm finished at 06:02 UT. An active interval with $\mathrm{AL} \sim-200 \mathrm{nT}$ ensued until a large, distinct $-946 \mathrm{nT}$ substorm (3) commenced during 17:00 UT. Variations in the $K_{p}$ index were consistent with the sequence of substorms. The first two substorms were associated with a decrease in the $D_{s t}$ index from $-10 \mathrm{nT}$ at 00:00-01:00 UT to $-42 \mathrm{nT}$ at 07:00-08:00 UT. $D_{s t}$ slowly increased beyond 12:00 UT.

The Los Alamos National Laboratory (LANL) satellites are in geosynchronous, equatorial orbits of radius $6.6 R_{E}$, corresponding to a magnetic latitude of $\sim-66.5^{\circ}$ in the radar observations. The Synchronous Orbit Particle Analyzers (SOPA) measured a succession of flux decreases and increases of outer radiation belt electrons in the energy range $50 \mathrm{KeV}$ and $26 \mathrm{MeV}$ associated with the three substorms. The horizontal bars in Fig. 1b indicated the approximate time intervals when major, rapid increases and decreases in energetic particle flux were observed. The final increase in particle flux associated with the first two substorms was detected by LANL 1991-080 during 07:12 to 08:15 UT. Thereafter, the LANL satellites detected a gradual halving of the particle fluxes during the radar observations of the AWFC.

A fluxgate magnetometer is located on Macquarie Is. (MQI) $\left(-65^{\circ}\right.$ magnetic), just to the east of TIGER beam 15 (see Fig. 8). MQI magnetic perturbations provide the most direct indication of ionospheric Hall current flow in

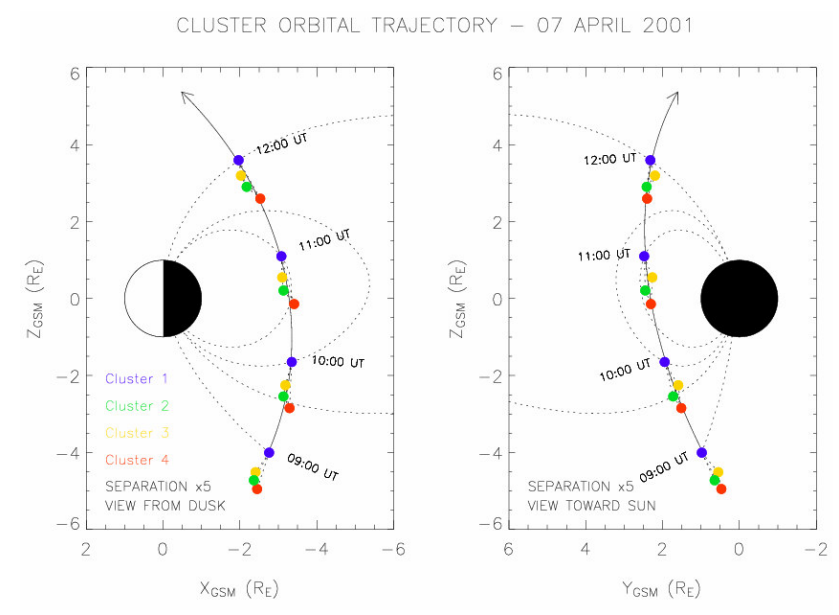

Fig. 2. The trajectory of Cluster 1 satellite in GSM coordinates during $\sim$ 09:00 to 12:00 UT on 7 April 2001. $X_{\mathrm{GSM}}$ is positive toward the Sun, $Y_{\mathrm{GSM}}$ is positive toward magnetic dusk, and $Z_{\mathrm{GSM}}$ is positive toward magnetic north. Cluster 1 locations are highlighted with blue dots at hourly intervals, and the relative locations of the other satellites are exaggerated by a factor of 5 .

proximity to TIGER. Figure $1 \mathrm{~b}$ is a summary plot of magnetic perturbations in the geomagnetic $X$ (North), $Y$ (East), and $Z$ (down) directions during 7 April. These components were de-spiked and then de-trended by subtracting a baseline defined by averaging their values over 5-9 April which included extended quiet intervals.

The AL index revealed a $-529 \mathrm{nT}$ substorm during 03:0006:00 UT. This substorm was detected as a coincident $343 \mathrm{nT}$ increase in the geomagnetic $X$ component by the MQI magnetometer, indicative of an enhanced eastward electrojet in the afternoon convection cell. Figure $1 \mathrm{~b}$ shows there was another increase in the $X$ component to $250 \mathrm{nT}$ during 07:01 to 07:46 UT. This corresponds to an enhancement of the eastward electrojet in the dusk convection cell. There was another 114-nT spike in the $X$ component at 09:52 UT.

During 05:00 to 10:00 UT, the $Z$ component was initially large and negative, but gradually converged upon the same small value as the $X$ component. This suggests the eastward electrojet was located several degrees equatorward of MQI, and then gradually contracted to the latitude of MQI $\left(-65^{\circ}\right)$. Beyond about 12:00 UT, the electrojet contracted poleward of MQI. Throughout the AWFC, the ionospheric Hall current fluctuated, but gradually became more negative, consistent with the rotation of MQI from the pre-midnight region dominated by the eastward electrojet toward the post-midnight region dominated by the westward electrojet.

\subsection{Cluster satellite observations}

The four Cluster satellites (Escoubet et al., 2001) underwent a perigee crossing of the nightside plasmasphere between $\sim$ 10:22 to 11:20 UT on 7 April 2001. Figure 2 shows the 
ELECTRIC FIELD SPECTROGRAM

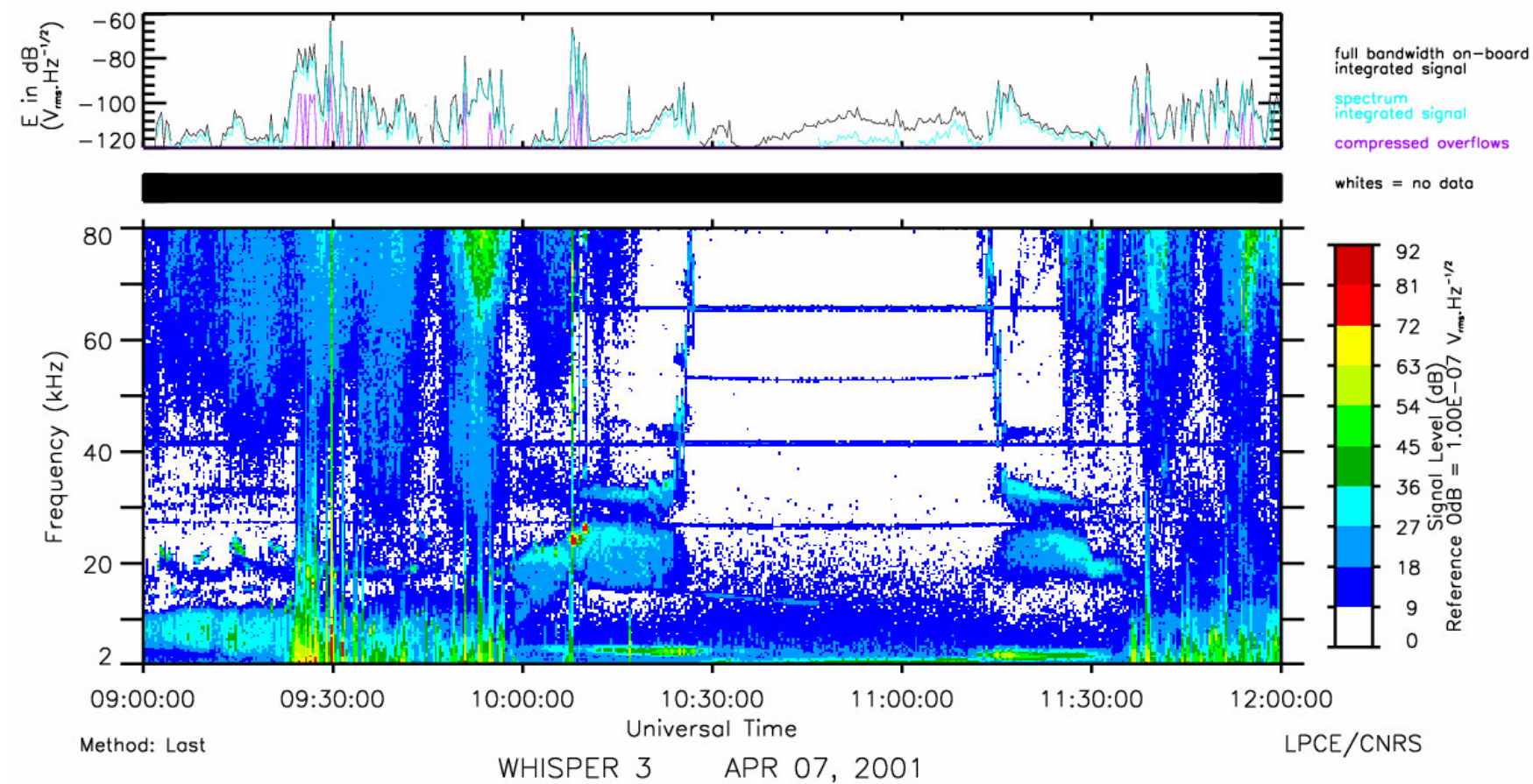

Fig. 3. Spectrogram of VLF signal strength measured by the WHISPER instrument on board the Cluster 3 satellite during $\sim 09: 00$ to 12:00 UT on 7 April 2001 (bottom panel). The signal strength integrated over the full receiver bandwidth is also shown (top panel). Plasmapause crossings occurred during 10:24-10:27 UT (entry) and 11:13-11:16 UT (exit).

trajectory of the reference satellite Cluster 1 (blue dots) during 09:00 to 12:00 UT in geocentric solar magnetospheric (GSM) coordinates. The relative location of the other Cluster satellites (colour coded) have been exaggerated by a factor of 5. Cluster 3 reached a perigee of $R \sim 4.0 R_{E}$ at $\sim 10: 42$ UT when it was located at $X=-3.26, Y=2.31$, and $Z=-0.36 R_{E}$ in geocentric solar ecliptic (GSE) coordinates. Near perigee, the planarity and elongation of the tetrahedron were $\sim 0.1$ and 0.8 , respectively (i.e. the four satellites were aligned like a string of beads with similar trajectories).

The magnetic field lines shown in Fig. 2 were traced using the T96 model parameterised by the lagged ACE solar wind conditions. These field lines indicate the equatorial plane of the dipole field and thus the peak ring current (RC) was encountered above the $X-Y$ GSM plane. The ionospheric footprint of the Cluster trajectories to be shown in Fig. 8 were also calculated using T96. Cluster 3 reached a minimum magnetic latitude of $-59.4^{\circ}$ and $\mathrm{L}$ shell of $\sim 5$ at $21: 40$ magnetic local time (MLT) and 10:44 UT. This corresponds to the outer plasmasphere.

The Waves of High frequency and Sounder for Probing Electron density by Relaxation (WHISPER) instrument (Décréau et al., 1993, 1997) was used to identify plasmapause locations. Trotignon et al. (2001) explains how the WHISPER measurements can be used to determine electron density, and Canu et al. (2001) discuss the natural plasma emissions observed close to the plasmapause. WHISPER data are extremely rich and the subject of ongoing interpretation, but the basic resonances observed in the ambient plasma include the plasma, electron gyro-, upper-hybrid, and Bernstein's mode frequencies. All of these resonances change in frequency with plasma density, except the electron gyrofrequency and its harmonics.

Figure 3 (bottom panel) presents a frequency versus time spectrogram from the WHISPER instrument on board the Cluster 3 spacecraft showing dynamic variations in $2-80 \mathrm{kHz}$ signal level during 09:00 to 12:00 UT on 7 April 2001. The almost continuous horizontal lines in the plot are resonances at the electron gyrofrequency and its harmonics. Plasmapause (PP) crossings were identified from the start (PPs) and finish ( $\operatorname{PP} f)$ times of the rapid increases (decreases) in the plasma, upper-hybrid, and Bernstein's mode frequencies during entry (exit) of the plasmasphere. These resonances become $>80 \mathrm{kHz}$ when Cluster was deep inside the plasmasphere. Table 1 lists the results, two sets for each satellite, comprising plasmasphere entry and exit times. Magnetic coordinates in the ionosphere were estimated using T96.

The Spatio-Temporal Analysis of Field Fluctuations (STAFF) instrument (Cornilleau-Wehrlin et al., 1997) measured bursts of $80 \mathrm{~Hz}$ to $>3 \mathrm{kHz}$ VLF electric and magnetic field activity confined to the outer plasmasphere, complementing the WHISPER plasmapause signatures. The 
Table 1. Plasmapause (PP) crossings determined using the Cluster WHISPER instrument.

\begin{tabular}{|c|c|c|c|c|}
\hline Satellite & PPs (Entry) & $\operatorname{PP} f$ (Entry) & PPs (Exit) & $\operatorname{PP} f$ (Exit) \\
\hline Cluster 2 & $10: 26 \mathrm{UT}-60.9^{\circ}, 21.8 \mathrm{MLT}$ & $10: 28 \mathrm{UT}-60.6^{\circ}, 21.7 \mathrm{MLT}$ & $11: 14 \mathrm{UT}-61.1^{\circ}, 21.5 \mathrm{MLT}$ & $11: 17 \mathrm{UT}-61.5^{\circ}, 21.5 \mathrm{MLT}$ \\
\hline Cluster 4 & $10: 27 \mathrm{UT}-60.5^{\circ}, 21.8 \mathrm{MLT}$ & $10: 31 \mathrm{UT}-60.1^{\circ}, 21.8 \mathrm{MLT}$ & $11: 16 \mathrm{UT}-61.6^{\circ}, 21.5 \mathrm{MLT}$ & $11: 20 \mathrm{UT}-62.1^{\circ}, 21.5 \mathrm{MLT}$ \\
\hline
\end{tabular}

Cluster Ion Spectrometry (CIS) instrument (Rème et al., 1997, 2001) measured the full 3-D distribution functions of major ions from thermal energies up to $\sim 40 \mathrm{keV}$. During 09:30 to 12:00 UT, the CIS-COmposition and DIstribution Function analyser (CODIF) measured peak ion fluxes in the energy range $\sim 1 \mathrm{keV}$ to $10 \mathrm{keV}$ in the plasma sheet-RC region, with the energy spread narrowing to $\sim 10 \mathrm{keV}$ within the outer plasmasphere $(L \sim 5)$. The peak ion fluxes are at higher energy than the two RC examples reported by Vallat et al. (2005), perhaps because the satellites penetrated to $L \sim 4$ for those events. The CIS-Hot Ion Analyser (HIA) measured peak ion densities of $\sim 110 \mathrm{~cm}^{-3}$ within the outer plasmasphere $(5 \mathrm{eV}-32 \mathrm{keV})$. These data sets are not shown for brevity.

The Cluster Flux Gate Magnetometer (FGM) instruments (Balogh et al., 1997, 2001) consist of two triaxial fluxgate magnetometers on each satellite. They provide up to $67 \mathrm{vec}-$ tor samples $\mathrm{s}^{-1}$ with high resolution, up to $8 \mathrm{pT}$. Vallet et al. (2005) have discussed the use of these magnetometer data and particle pressure data to calculate current densities. They demonstrated the use of the curlometer technique to estimate $\mathrm{RC}$ densities during Cluster perigee passes. They measured filamentary structures concentrated in the plasma sheet, but also in the RC. However, the curlometer technique assumes all four satellites lie within the same current sheet, and was not used here because of the relatively large elongation of the tetrahedron. The satellite separations were also up to $\sim 10^{3} \mathrm{~km}$, too large for reliable curlometery.

However, Ampere's right-hand rule for magnetic circulation was used to gain insights into the relative locations of FAC and the RC. First, the large-scale secular magnetic field was modelled using T96 and appropriate solar wind parameters. These large-scale fields were subtracted from the FGM measurements to obtain perturbations about the model values. The amplitude of the large-scale T96 fields were $\sim 500 \mathrm{nT}$, whereas the FGM perturbations were only in the order of $10 \mathrm{nT}(\sim 2 \%)$. Figure 4 shows the Cluster 3 FGM perturbations in the GSM coordinate system.

Figure $4 \mathrm{~d}$ shows that $\Delta B_{\text {Total }}$ had local maxima at $\sim 09: 45$ and 11:40 UT, with crossings of the origin at 10:04 and 11:27 UT, outside of the WHISPER plasmasphere (Table 1). The main feature of $\Delta B_{\text {Total }}$ was a negative dip to a minimum value of $-21 \mathrm{nT}$ located at 10:40 UT, near to the time

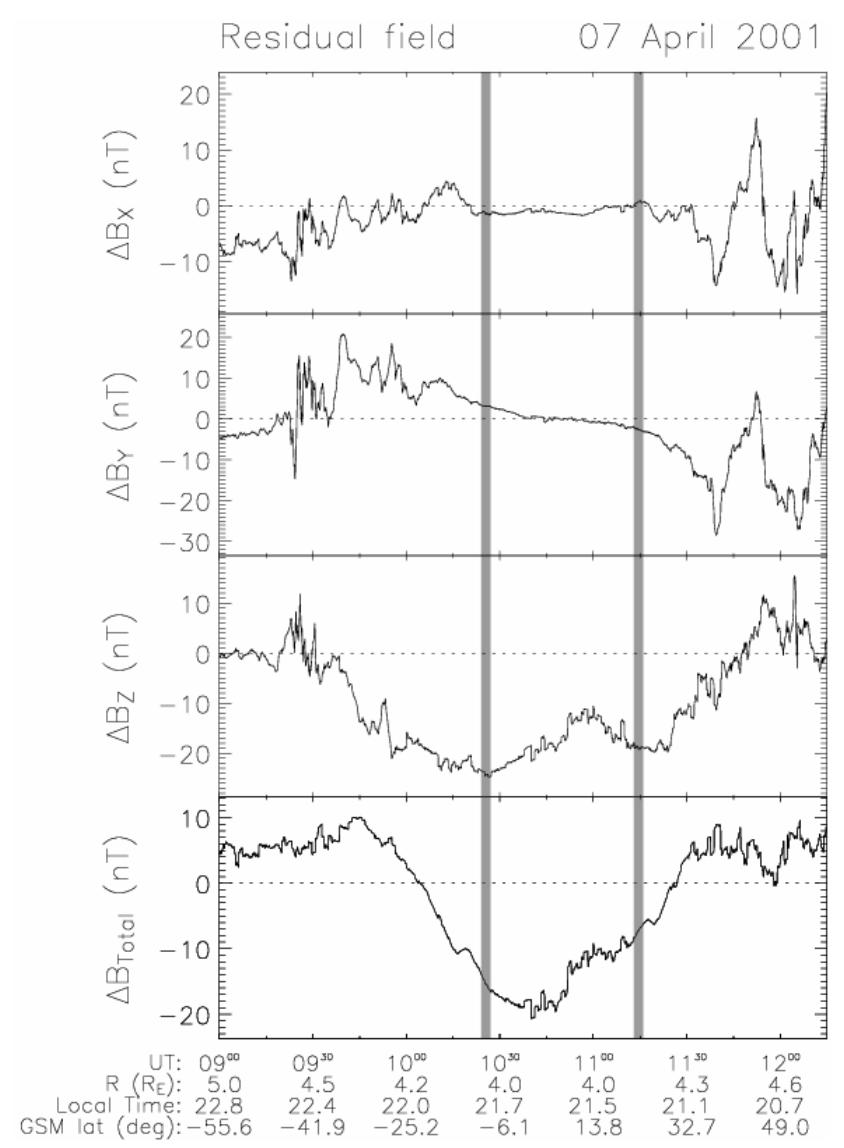

Fig. 4. GSM magnetic field perturbations, $\Delta B_{x}, \Delta B_{y}, \Delta B_{z}$, and $\Delta B_{\text {Total }}$ (top to bottom) inferred using the FGM instrument on board the Cluster 3 satellite during 09:00 to 12:15 UT on 7 April 2001. The perturbations were estimated by subtracting a T96 model of the smooth, large-scale magnetic field variations. Figure 2 shows the Cluster 3 perigee was at $\sim 10: 42$ UT and Fig. 3 shows there were plasmapause crossings during 10:24-10:27 UT (entry) and 11:1311:16 UT (exit). The plasmapause crossings have been shaded in this figure.

of perigee. The decrease in $\Delta B_{\text {Total }}$ was mostly due to a decrease in GSM $\Delta B_{z}$ to a minimum of $-25 \mathrm{nT}$ attained at 10:27 UT. However, the $\Delta B_{\text {Total }}$ decrease exhibited greater symmetry about the time of the perigee crossing. 


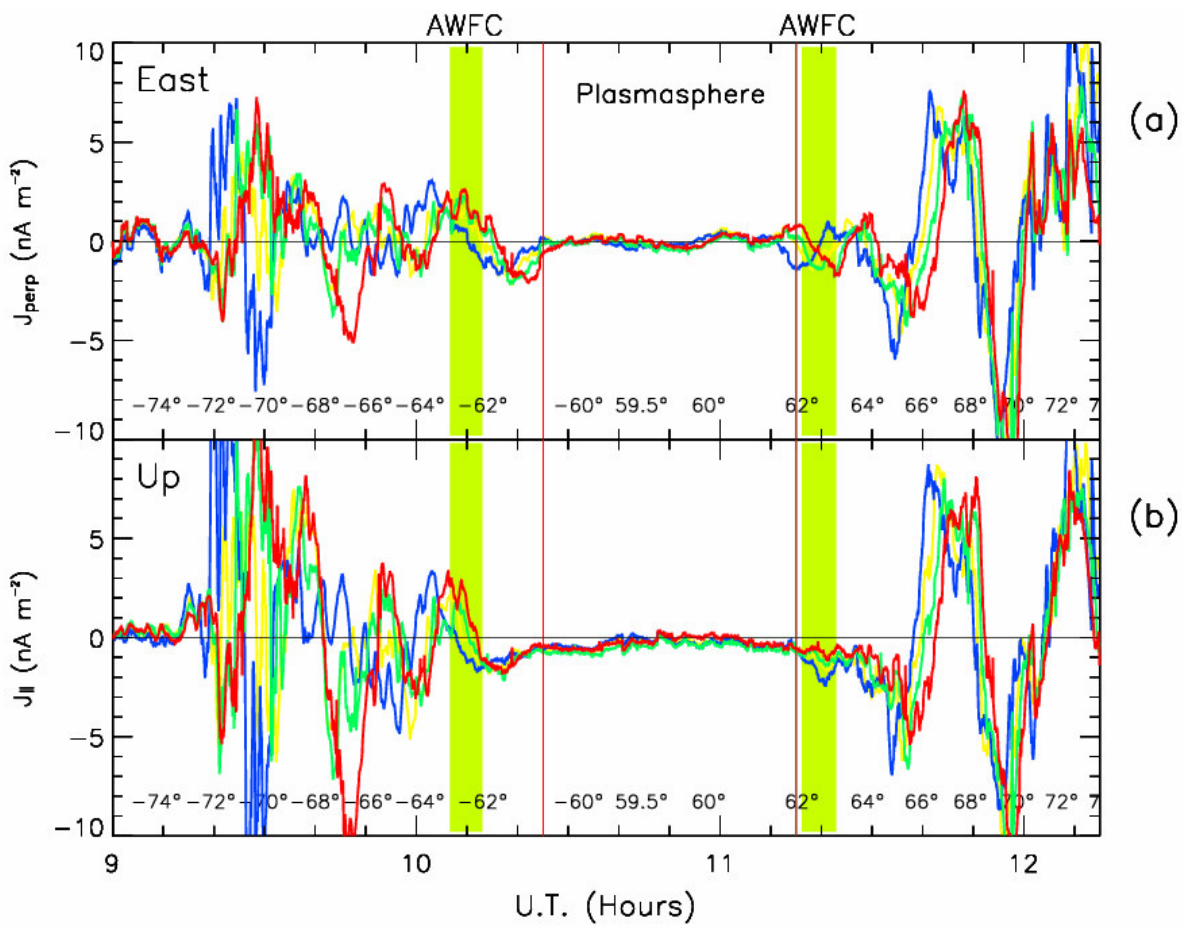

Fig. 5. Rough estimates of FAC densities obtained by applying Ampere's law to FGM magnetic field perturbations shown in Fig. 4. The results do not allow for the oblique geometry of the orbits and are shown for all four satellites: Cluster 1 (blue), Cluster 2 (green), Cluster 3 (yellow), and Cluster 4 (red). (a) The azimuthal current estimated using $J_{\perp}=\Delta B_{x} / d s$, and (b) the FAC estimated using $J_{\| \mid}=\Delta B_{y} / d s$ where $s$ is spatial distance along the satellite trajectory. These results have been smoothed on a scale of $\sim 2000 \mathrm{~km}$ in an attempt to recover the large-scale features.

A magnetic field model is more likely to be accurate at $\sim 4 R_{E}$ than further away in the dynamic plasma sheet. Clearly, the decrease in $\Delta B_{\text {Total }}$ and $\Delta B_{z}$ indicates the T96 model overestimated the magnetic field strength within the plasmasphere. The RC flows toward the west $(+Y)$, and will enhance (suppress) $\Delta B_{z}$ measured at a greater (lesser) radial distance than the RC. The decreases in $\Delta B_{\text {Total }}$ and $\Delta B_{z}$ are taken to indicate a stronger $\mathrm{RC}$ effect than allowed for in T96. Figure 4, and similar results for the other Cluster satellites, suggest a RC enhancement was concentrated near 4.1-4.3 $R_{E}$ with its near-Earth edge overlapping the plasmapause located at $4.1 R_{E}$.

In the case of a polar low Earth orbit (LEO) satellite traversing geomagnetic field lines orthoganol to the Earth's surface, the presence of an infinite FAC sheet can be inferred by applying Ampere's right-hand rule to the $\Delta B_{y}$ component. FAC away from the ionosphere should occur where $\Delta B_{y} / d s>0$, and FAC toward the ionosphere should occur where $\Delta B_{y} / d s<0$. Here $s$ is spatial distance along the satellite trajectory, increasing in the GSM $Z$ direction. Similarly, the presence of azimuthal (zonal) field perpendicular current sheet can be inferred from the $\Delta B_{x}$ component. Current flow toward the east should occur where $\Delta B_{x} / d s>0$, and toward the west where $\Delta B_{x} / d s<0$.
Figure 5 estimates currents in this way for all four satellites. The Cluster orbits were thought of as slices confined within the GSM $X-Z$ plane to simplify the analysis, and the changing speed of the satellites along their trajectories was allowed for. However, the results are merely indicative of real FAC for the following reasons. (i) The high altitude Cluster trajectories intersect the main geomagnetic field in a different way to the geometry of LEO measurements. E.g. the magnitude of the currents near to Cluster perigees were probably greater than indicated because the satellites became parallel to the magnetic field. (ii) FACs located at $4-5 R_{E}$ are located above the auroral acceleration region, and thus should differ from FACs in the topside ionosphere inferred using Iridium magnetometer measurements. (iii) The FAC sheets were not infinite in extent.

Nevertheless, this first-order analysis provides clues about the relation between AWFC and plasma sheet currents. The magnetic derivatives were extremely bursty when examined at a temporal resolution equivalent to the spin-period of the spacecraft $(\sim 4 s)$. The inferred current sheets were also inconsistent from one satellite to the next during the inbound passage through the auroral region, $\sim-72^{\circ}$ to $-64^{\circ}$ magnetic. Hence the currents shown in Fig. 5 were smoothed at a temporal scale of 412-s, corresponding to a spatial scale 
of $\sim 2000 \mathrm{~km}$, to reveal any large-scale features. The strong filamentation of the currents is consistent with the multifractal properties of the plasma sheet (Lui, 2002). The filamentation of the current decreased upon entry into the RCplasmasphere region, as found by Vallat et al. (2005).

Figure 5 suggests the AWFC (shaded) was located at the transition between a downward FAC at $\sim-62^{\circ}$ and an upward FAC at $\sim-64^{\circ}$ during the inbound crossing (however, note the filamentation of the currents at this time). Figure 5 also suggests the AWFC was located at the equatorward edge of a downward current which increased in magnitude further poleward during the outbound crossing. The AWFC and Cluster measurements were made in opposite hemispheres during the outbound crossing. Figure 9 will reveal the AWFC was far more intense at the time of the inbound crossing than the outbound crossing. However, the FACs were more coherent and stable during the outbound crossing; hence the notion of a large-scale FAC was more meaningful. Figure 8 will show the AWFC was coincident with downward Region 2 current.

Lui et al. (2002) used a sign singularity analysis to show how the plasma sheet evolved from random-like Brownian motion fluctuations before substorm onset, to full-scale MHD turbulence during current disruption. Large-scale coherent structures formed during the substorm recovery phase. In our event, the filamentation of the auroral current sheets was stronger during the inbound passes of Cluster than the outbound passes, and suggests the gradual formation of large-scale coherent structure during the declining phase of the AWFC, again suggesting an intimate relationship to substorm dynamics.

\subsection{IMAGE EUV satellite observations}

The IMAGE Extreme Ultraviolet Imager (EUV) (Sandel et al., 2000) images the distribution of $\mathrm{He}^{+}$in Earth's plasmasphere by detecting its resonantly-scattered emission at $30.4 \mathrm{~nm}$. The plasmaspheric $\mathrm{He}^{+}$emission brightness is directly proportional to the $\mathrm{He}^{+}$column abundance, and thus can be used to estimate plasmapause location. Near apogee the wide field of view of the EUV imager provides global snapshots of the plasmasphere once every ten minutes. Figure 6 is a representative EUV image recorded at 10:32 UT (centre time) on 7 April when IMAGE was located in the Northern Hemisphere at GSE $X=3.53, Y=2.30$, and $Z=6.12 R_{E}$ in GSE coordinates, having passed through apogee at $8.1 R_{E}$.

Sandel et al. (2001) describe the main features visible in EUV images. In Fig. 6, the Sun is located toward the bottom and the brightest ring is day glow. The Earth's shadow points toward the top and a faint image of the auroral oval can be seen displaced toward this shadow. Dusk is toward the right and a plasmaspheric drainage plume sweeps back toward the Sun. The plasmapause associated with the drainage plume was most irregular near midnight and then became increas-

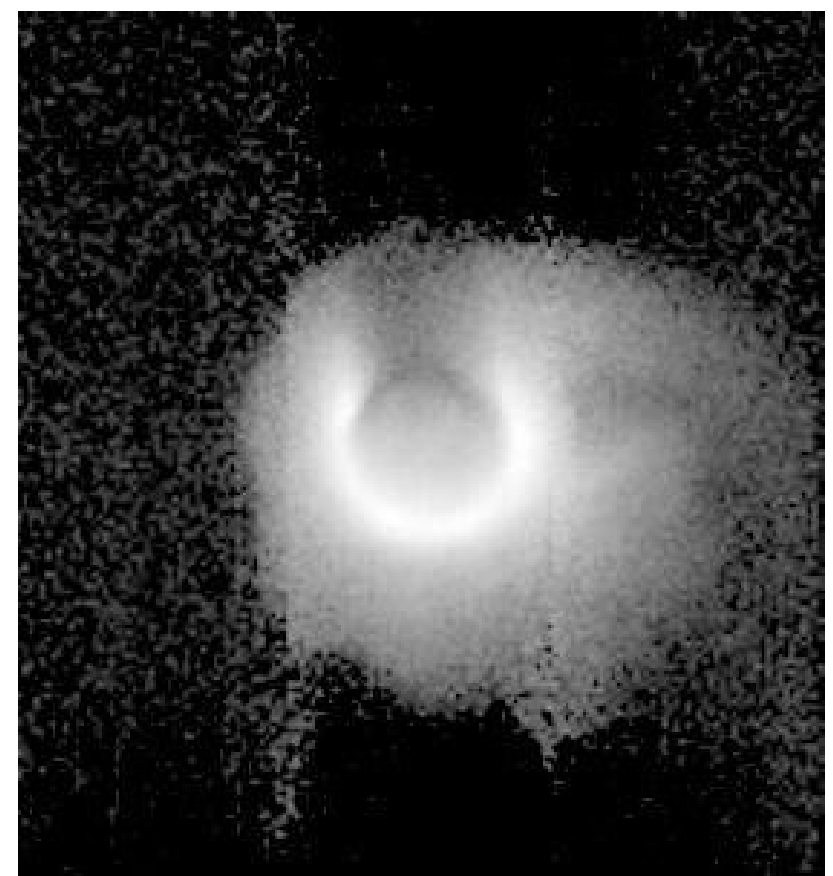

Fig. 6. IMAGE EUV image recorded at 10:32 UT (centre time) on 7 April 2001 when IMAGE was located just past apogee in the Northern Hemisphere.

ingly diffuse at earlier MLT. Other notches and shoulders are visible along the dayside plasmapause.

It will be shown that the AWFC was located in the dusk-tomidnight sector, just beyond the plasmapause associated with the drainage plume (Fig. 6, top right quadrant). The plasmapause boundary often formed a "straight edge" extending from near midnight along the outer edge of the drainage plume. The AWFC may have been associated with this feature.

The latest version of the "euv_imtool" software available from the IMAGE EUV web page was used to manually scale the location of the relevant plasmapause boundary. The software calculated the minimum $L$ shell and magnetic longitude for every mouse click. These points were then mapped to magnetic latitude in the ionosphere using the IGRF model which does not allow for the effects of external currents. However, the Cluster WHISPER plasmapause locations were mapped to the ionosphere using T96. Hence the Cluster plasmapause locations were used to correct the IMAGE EUV plasmapause locations. This involved applying a systematic $\sim 1^{\circ}$ poleward shift to the latter. The IMAGE EUV results have been overlaid using bold black triangles in subsequent figures.

\subsection{Iridium ${ }^{\circledR}$ satellite observations}

The Iridium satellite constellation consist of 66 satellites in $780-\mathrm{km}$ altitude polar orbits arranged in six equally 


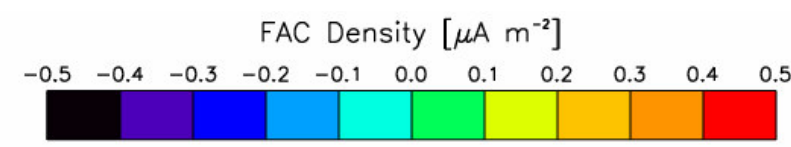

(a) 09:00 UT

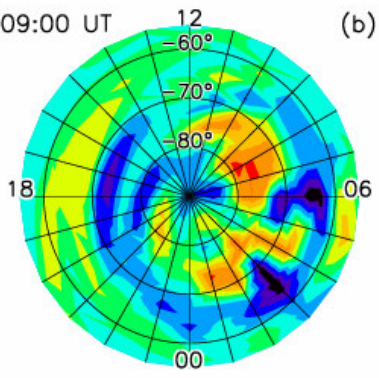

(b) 09:30 UT

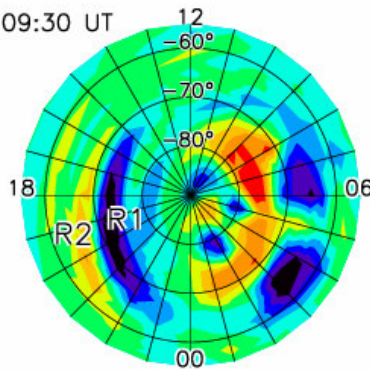

(c)

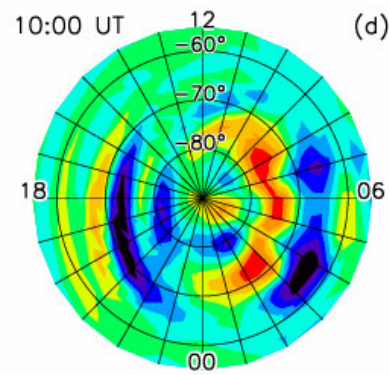

(d)

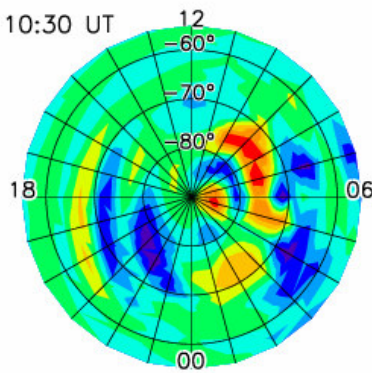

(e)

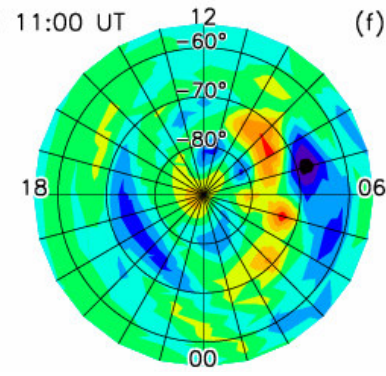

(f) $11: 30$ UT

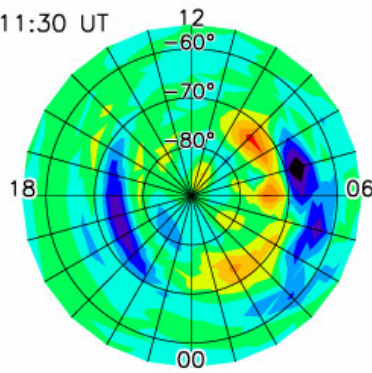

Fig. 7. Southern Hemisphere maps of FAC density calculated using Iridium satellite measurements of cross-track magnetic field perturbations. The calculations were made using an accumulation time of $\sim 1 \mathrm{~h}$, and the resolution is $\sim 4^{\circ}$ in latitude and $\sim 2 \mathrm{~h}$ in MLT. The results are presented in the form of a 24-h clock dial plot of MLT and AACGM latitude from $-50^{\circ}$ to the pole. The sign convention used is positive (red) for current into the ionosphere, and negative (blue) for current out of the ionosphere. The dusk sector Region 1 and 2 FACs are labelled "R1" and "R2", respectively.

spaced planes. Iridium engineering magnetometers measure the cross-track magnetic field perturbations with sufficient sensitivity to infer large-scale ionospheric FAC. Waters et al. (2001) combined the cross-track perturbations measured by all satellites using a spherical harmonic fit, and then Ampere's law was used to obtain the global-scale distribution of FAC. The low sampling rate of the Iridium magnetometers mean that the magnetometer perturbations are aliased at resolutions less than $\sim 4^{\circ}$ in latitude and the samples must be accumulated for $\sim 1 \mathrm{~h}$ to construct a single global-scale map. FACs are well known to evolve on time scales $<1 \mathrm{~h}$.
This technique was used to calculate maps of FAC for the present event. Figure 7 is a sequence of six FAC maps encompassing the interval 08:30 to 12:00 UT during which time TIGER observed an AWFC. The time stamp "09:00 UT" actually means the FAC current map calculated using the available Iridium perturbations accumulated during 08:30 to 09:30 UT. The results are presented as a polar plot of AACGM latitude versus MLT. The sign convention used is positive (red) for current into the ionosphere, and negative (blue) for current out of the ionosphere. The colour bar means that a FAC density in the range $>0.3$ to $0.4 \mu \mathrm{A} \mathrm{m}^{-2}$ is coloured orange and FAC greater than $0.4 \mu \mathrm{A} \mathrm{m}^{-2}$ is coloured red.

At 09:30 UT, a dusk sector Region 1 current (Iijima and Potemra, 1978) was strongest $\left(<-0.5 \mu \mathrm{A} \mathrm{m}^{-2}\right)$ between $\sim$ 15:00-23:00 MLT at $\sim-72^{\circ}$ magnetic. This FAC swept to lower latitude at later MLT, and its intensity peaked at 09:30 UT. It was still relatively strong at 10:00 UT, but was clearly reduced in spatial extent and strength by 10:30 UT. This FAC was weakest at 11:00 UT, but intensified again at 11:30 UT. An additional upward FAC was located at $\sim 18 \mathrm{MLT}$ and $-81^{\circ}$ at 09:00 UT. It peaked in intensity at 10:30 UT but at lower latitude and later MLT.

The dusk sector upward Region 1 current was flanked by a weaker downward Region 2 current $\left(<0.3 \mu \mathrm{A} \mathrm{m}^{-2}\right)$ located at $\sim-65^{\circ}$. Like the Region 1 current, the Region 2 current also swept to lower latitude at later MLT, and it peaked at 09:30 UT. Thereafter it gradually decreased in intensity until it became very weak, $<0.1 \mu \mathrm{A} \mathrm{m}^{-2}$, and was replaced by regions of very weak upward current. The Region 2 current is thought to be related to closure of the partial RC, so the variations shown in Fig. 7 may be partly related to variations in the RC intensity.

The dawn sector FACs are important, but were not coincident with the radar observations. Basically, they consisted of downward Region 1 currents poleward of $\sim-70^{\circ}$ and upward Region 2 currents equatorward of $\sim-70^{\circ}$. Like the dusk sector FACs, they were strongest at 09:30 UT, decayed toward a minimum at 10:30 UT, and then resurged at 11:30 UT. The dawn sector FACs tended to be more patchy, split into two or three main regions spread in longitude. Localised "hot spots" of FAC occurred, for example, $<-0.5 \mu \mathrm{A} \mathrm{m}^{-2}$ located at $\sim 03: 30$ MLT and $-64^{\circ}$ at 09:30 UT.

Contours of the FAC shown in Fig. 7 will be overlaid in subsequent figures showing the HF radar observations. Keeping in mind the limited spatial and temporal resolution of the FAC maps, they suggest a relationship between the intensity of the dusk sector Region 2 current and the intensity of the AWFC.

\subsection{TIGER radar observations}

It is accepted that SuperDARN radars measure the line-ofsight (LOS) component of $\boldsymbol{E} \times \boldsymbol{B} / B^{2}$ drift in the F-region 
(Villain et al., 1985). Figure 8 illustrates the relationship between TIGER LOS observations of an AWFC and various satellite results. The radar field of view (FoV) was mapped to a polar plot of AACGM latitude versus MLT in the duskto-midnight sector. The coloured pixels within the FoV represent LOS Doppler velocity ( $\left.v_{\mathrm{LOS}}\right)$ for typical 2-min full scans commencing at (a) 09:30 UT and (b) 10:30 UT on 7 April 2001. The sign convention used for $v_{\mathrm{LOS}}$ is positive (red) toward the radar, and negative (black) away from the radar.

The variations in TIGER $v_{\mathrm{LOS}}$ are consistent with antisunward flows poleward of $-75^{\circ}$, and an AWFC centred on $\sim-63^{\circ}$. That is, the low latitude scatter consisted of a patch with approaching $v_{\mathrm{LOS}}>360 \mathrm{~m} \mathrm{~s}^{-1}$ (red) on the eastern most beams, and a patch with receding $v_{\mathrm{LOS}}<-280 \mathrm{~m} \mathrm{~s}^{-1}$ (black) on the western most beams. The convection speeds also decreased both equatorward and poleward of the centre of the AWFC, and the AWFC tended to recede to higher latitude toward the west. Finally, the backscatter powers (irregularity intensity) were weakest on beam 5 orthogonal to the flow. All of these characteristics are the same as reported in previous studies (Parkinson et al., 2003a, 2005a).

The Special Sensor-Ions, Electrons, and Scintillation (SSIES) instruments on board the DMSP satellites provided measurements of ion drift velocity in the top side ionosphere at altitude $830 \mathrm{~km}$. The velocity component transverse to the satellite trajectory, $V_{y}$, is the most reliable component. Because of the finite number of spacecraft and their Sun synchronous orbits, a limited number of trajectories were coincident with the radar observations per night. A DMSP F12 pass at $\sim 08: 52$ UT is superimposed in Fig. 8a, and a F14 pass at $\sim 10: 30$ UT and a F12 pass at $\sim 10: 34$ UT are superimposed in part (b). The 2-D circulation is not given by $V_{y}$ measurements alone, but they are consistent with an extended region of anti-sunward flow across the polar cap, and return sunward flow in the dusk sector. AWFCs are structures embedded within the equatorward portion of this return sunward flow. For example, the narrow spike in the F12 measurements (Fig. 8a) suggests the AWFC may have originated at a lower latitude at later local times.

The magnetic footprint of the Cluster 3 spacecraft is superimposed using bold black dots. The footprints fluctuate on a time scale of $64 \mathrm{~s}$ because ACE solar wind measurements were used to drive the T96 model. The Cluster 3 trajectory advanced in time from later to earlier MLT (from right to left), reaching its lowest latitude of $-59.4^{\circ}$ at 10:44 UT (21:40 MLT). Recall Fig. 2 showed the Cluster spacecraft traversed the northern magnetosphere after perigee. Although the Cluster trajectories mapped to within the TIGER FoV, they were located to the east of beam 15 at perigee. The AWFC was decaying and relatively weak at this time.

The bold "nodules" on the Cluster footprints at latitude $\sim-61^{\circ}$ represent WHISPER plasmapause locations (Table 1). The nodules were caused by merging of the four, circular bold dots corresponding to successive Cluster plasma-

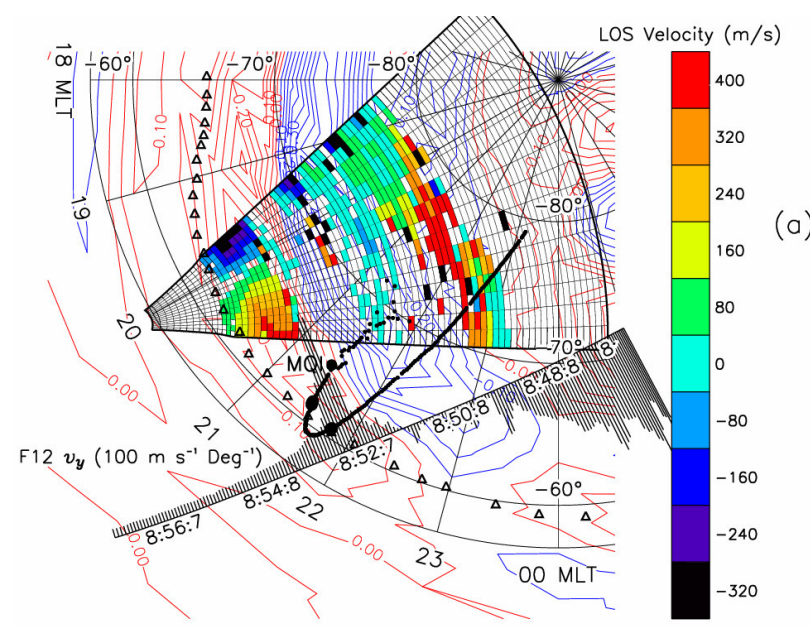

(a)

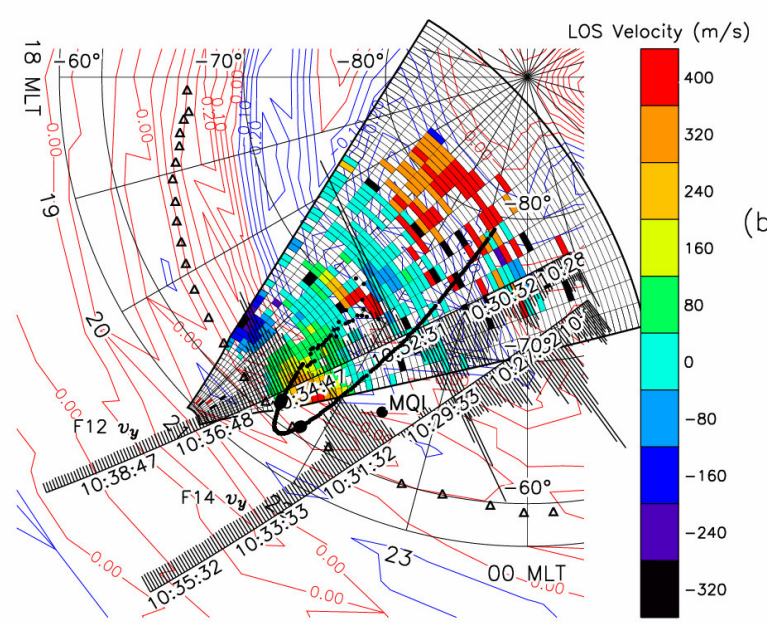

(b)

Fig. 8. (a) TIGER radar observations of LOS Doppler velocity measured during the full scan commencing at 09:30 UT on 7 April 2001. Warm, red colours represent motion toward the radar and cold, blue colours represent motion away from the radar. The relative location of Macquarie Island (MQI) and the magnetic footprint of the Cluster 3 orbit are shown (bold dots). The bold triangles represent plasmapause locations estimated using IMAGE EUV observations (cf. Fig. 6). The background contours represent the FAC density calculated using Iridium satellite measurements at 09:30 UT (cf. Fig. 7b). DMSP F12 measurements of ion drift velocity transverse to the satellite trajectory at 4 -s resolution have been superimposed using a scale of $100 \mathrm{~m} \mathrm{~s}^{-1}{ }^{\circ} \Lambda^{-1}$. (b) The same except the TIGER observations for the full scan commencing at 10:30 UT and the FAC density calculated using Iridium satellite measurements at 10:30 UT (cf. Fig. 7d). DMSP F12 and F14 ion drift measurements have been superimposed.

pause crossings. To a first reasonable approximation, the successive Cluster observations demonstrate the plasmapause was stationary. The bold, black triangles represent locations of the plasmapause estimated using the IMAGE EUV images with centre times of (a) 09:32 UT and (b) 10:33 UT. They extended to higher latitude at earlier MLT consistent with the 


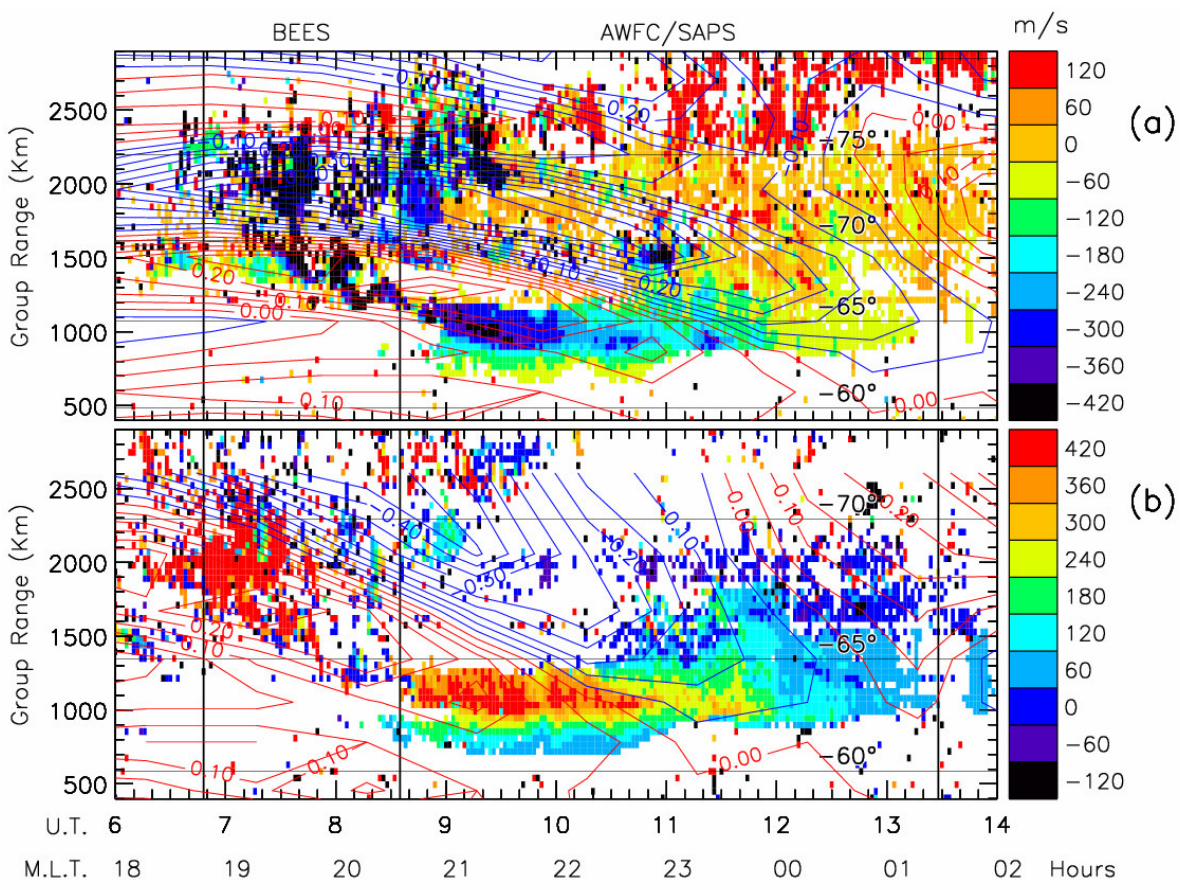

Fig. 9. (a) Range-time plot of the LOS Doppler velocity $\left(\mathrm{m} \mathrm{s}^{-1}\right)$ measured on TIGER beam 0 during 06:00-14:00 UT on 7 April 2001. Thin vertical lines delineate nominal intervals corresponding to the BEES ( 07:03-08:35 UT) and AWFC ( 08:35-13:28 UT). The background contours represent the FAC density calculated using Iridium satellite measurements at 09:30 UT (cf. Fig. 7b). The contours were shifted in time to provide a rough indication of the FAC that would be observed on beam 0 . (b) The LOS Doppler velocity ( $\mathrm{m} \mathrm{s}^{-1}$ ) measured on the TIGER beam 15. Note that the background contours were shifted by a different amount to provide a rough indication of the FAC that would be observed on beam 15. Thin, black, horizontal lines represent magnetic latitudes, and nominal values of MLT above MQI are also given.

diffuse drainage plume illustrated in Fig. 6. It was not possible to estimate the plasmapause locations at earlier MLT than shown because the drainage plume extended beyond the FoV of the EUV imaging system.

It is clear the peak AWFC flows were located $\sim 2^{\circ}$ poleward of the plasmapause, with the equatorward edge of the AWFC overlapping the plasmapause.

The background contours represent the FAC at (a) 09:30 UT and (b) 10:30 UT obtained using the Iridium satellite constellation (cf. Figs. 7b, d). The contours are separated by $0.05 \mu \mathrm{A} \mathrm{m}^{-2}$ and they are coloured red (blue) for downward (upward) FAC. The Iridium-based maps of FAC used 1-h accumulation intervals, whereas the individual radar scans took $2 \mathrm{~min}$. However, the basic Region 1 and Region 2 current morphology persisted when the Iridium perturbations were analysed using a shorter accumulation time of only $30 \mathrm{~min}$, and the AWFC was a persistent feature across numerous full scans. It is reasonable to compare the basic large-scale phenomenology, but no doubt new physics will be revealed by improving the spatial and temporal resolution of all the data sets.

In both full scans, the AWFC occurred close to the peak Region 2 downward current of magnitude $\sim 0.3 \mu \mathrm{A} \mathrm{m}^{-2}$, well equatorward of the peak Region 1 upward current. The latitudinal peaks of both the AWFC and the Region 2 cur- rent were centred poleward of the plasmapause. However, the equatorward decay of the AWFC and the Region 2 current overlapped the plasmapause. The plasmapause, AWFC, and Region 1 and 2 currents all receded to higher latitude at earlier MLT.

Dynamic energy spectra of precipitating ions and electrons determined using the DMSP SS J/4 detectors (Hardy et al., 1984) are available online. The DMSP F13 satellite traversed the austral auroral oval from 20:08 to 19:00 MLT during 10:03 to 10:07 UT. The corresponding spectrogram showed a sharp decrease in the energetic electron precipitation equatorward of $-65^{\circ}$. Newell et al. (1996) describe the algorithm used to automatically identifying various auroral boundaries. The b2e boundary, one interpretation of the start of the plasma sheet, was located at $-66.1^{\circ}$ and 19:06 MLT. The b2i point, the point where the energy flux of ions above $3 \mathrm{keV}$ has a maximum, was located at $-65.2^{\circ}$ and 19:00 MLT. Actually, a nose of $\sim 10 \mathrm{keV}$ ion precipitation extended equatorward to $-63.6^{\circ}$. Clearly, the SS J/4 results confirm the AWFC was located equatorward of the main electron precipitation, and in a region of downward FAC sometimes associated with $\sim 10 \mathrm{keV}$ ion precipitation. 


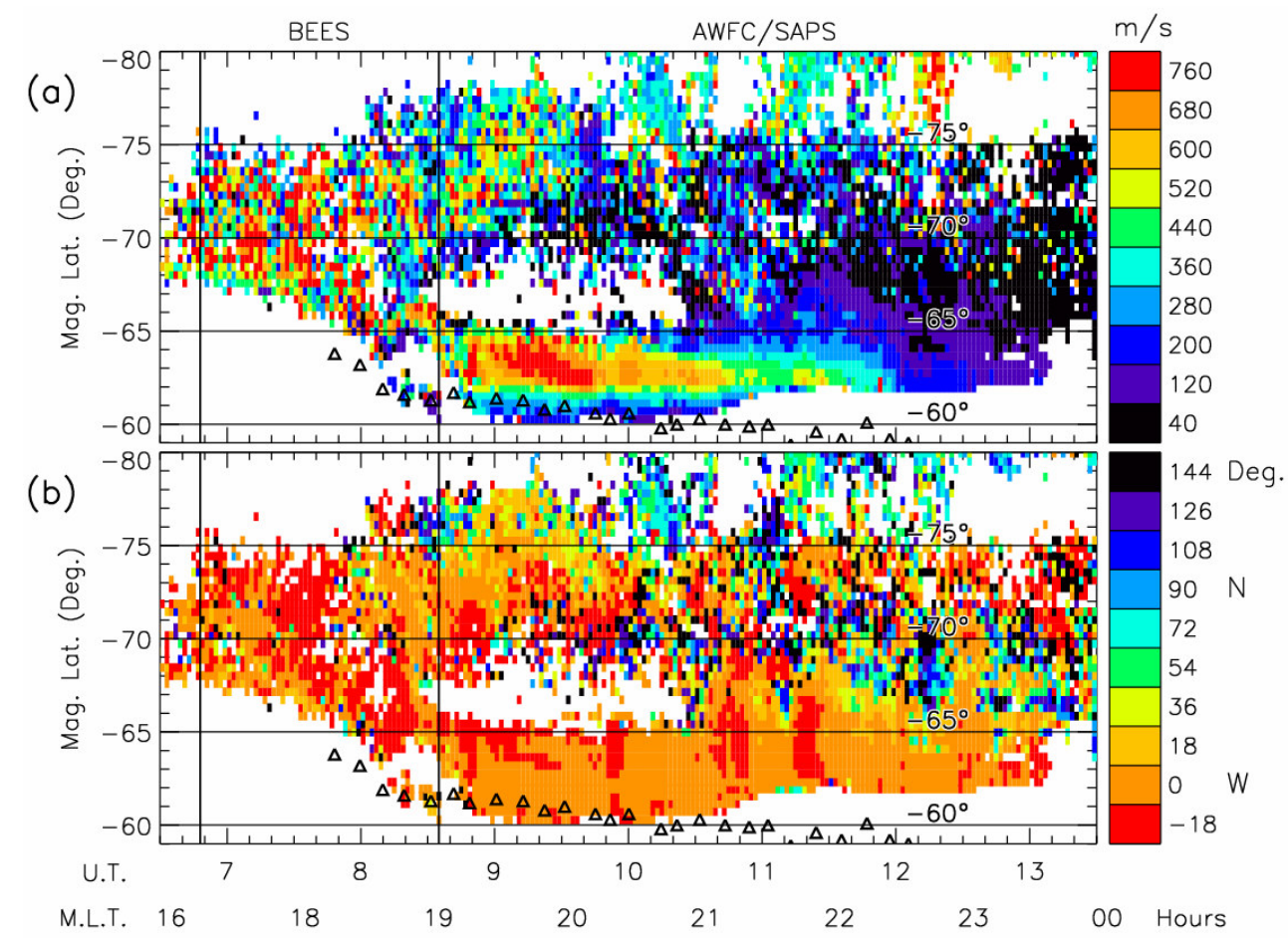

Fig. 10. Two-dimensional flow vectors estimated along TIGER beam 4 using the beam-swinging technique at 2-min time resolution and $0.4^{\circ}$ latitude resolution during 07:00-13:00 UT on 7 April 2001. (a) The flow speed is represented using a colour scale with steps of 80 $\mathrm{m} \mathrm{s}^{-1}$. All speeds $>720 \mathrm{~m} \mathrm{~s}^{-1}$ have been coloured red. (b) The flow direction is represented by a colour scale using steps of $18^{\circ}$ where azimuth $0^{\circ}$ is toward magnetic west and azimuth $90^{\circ}$ is toward magnetic north (equatorward). Within the flow channel, the flows were predominately westward, though tending slightly poleward. Thin vertical lines delineate nominal intervals corresponding to the BEES ( 07:03-08:35 UT) and AWFC ( 08:35-13:28 UT). The bold triangles represent plasmapause locations estimated at the longitude of beam 4 using IMAGE EUV observations.

\subsection{TIGER summary plots}

Figures $9 \mathrm{a}$ and $\mathrm{b}$ are summary plots of TIGER $v_{\mathrm{LOS}}$ observations made during 06:00-14:00 UT on 7 April 2001. Panels (a) and (b) show the results for beams 0 and 15 , the western and eastern most beams, respectively (cf. Fig. 8). The two colour scales have been adjusted to permit direct comparison of the $v_{\text {LOS }}$ amplitudes. Nominal values of MLT above MQI are given beneath the UT time scale, and AACGM latitudes have been superimposed. Qualitatively, the observations reveal a "jet-like" AWFC (Parkinson et al., 2006).

AWFCs and PJ/SAIDs have peak occurrence in the premidnight sector (Karlsson et al., 1998), and HF radars have preferred range windows for detecting ionospheric scatter determined by the magnetic field geometry and prevailing propagation conditions (Parkinson et al., 2003b). The radar operating frequency was fixed within the band 11400 $11650 \mathrm{kHz}$ for the duration of the experiment. The AWFC was not observed within a preferred range window until $\sim 08: 35$ UT, but intense AWFCs may have been synchronised with Substorms $1 \& 2$, yet were not observed by TIGER because they occurred too early in UT and at too low a latitude anyway.
The main feature of Fig. 9a is the channel of scatter with strong receding velocity, nominally commencing at 08:45 UT, peaking at $\sim 09: 20 \mathrm{UT}$, remaining strong $\left(<-390 \mathrm{~m} \mathrm{~s}^{-1}\right)$ until $\sim 09: 37 \mathrm{UT}$, and then gradually decaying until the loss of scatter at 13:16 UT. Similarly, the main feature in Fig. 9b is the channel of scatter with strong approaching velocity, nominally commencing at 08:35 UT, peaking during $\sim 09: 00$ to 09:40 UT, remaining strong ( $>390 \mathrm{~m} \mathrm{~s}^{-1}$ ) until $\sim 10: 45 \mathrm{UT}$, and then gradually decaying until the loss of scatter at 13:28 UT. Figure 9a shows the flow channel was basically centred on $\sim-64^{\circ}$ whereas panel (b) shows the flow channel was centred on $\sim-63^{\circ}$. The spatial orientation of the AWFC was toward slightly higher latitude at earlier MLT.

Combined, the beam 0 and 15 observations of $v_{\text {LOS }}$ imply the existence of a jet-like AWFC during 08:35 to 13:28 UT. As with earlier events (Parkinson et al., 2003a, 2005a), the AWFC velocities quickly grew to peak values during an interval of $\sim 10 \mathrm{~min}$, persisted at those values for in the order of $1 \mathrm{~h}$, and then gradually decayed throughout the remainder of the event. The $v_{\text {LOS }}$ values reached lower values on beam 0 more quickly because this beam was more orthogonal to the AWFC. Whilst peak $v_{\text {LOS }}$ values were modest at 
$\sim 500 \mathrm{~m} \mathrm{~s}^{-1}$, they imply much stronger westward flow when allowing for the oblique angle between the radar beams and AWFC.

For this particular event, the equatorward limit of scatter was probably limited by the prevailing HF propagation conditions at 11 400-11650 kHz. Hence decametre-scale irregularities and another detached flow channel may have been detected by a hypothetical radar located further equatorward. However, the observed $v_{\text {LOS }}$ values decayed both poleward and equatorward of the AWFC reported here, so it was a separate flow channel.

The $v_{\text {LOS }}$ observations revealed another important aspect of the AWFC evolution. Figure 9 shows that commencing near to 07:01 UT, and possibly earlier, a band of ionospheric scatter with large $\left|v_{\text {LOS }}\right|$ oscillated in latitude, but generally expanded equatorward, merging into the nominal start of the AWFC at 08:35 UT. This feature is annotated in Fig. 9 with "BEES," a band of equatorward expanding scatter. The BEES was especially well defined on beam 0 , but was observed on all beams, implying the feature had a zonal extent $>2 \mathrm{~h}$. Qualitatively, the AWFC was a continuation of the BEES. Once formed, the centre of the AWFC continued to expand equatorward for $\sim 1^{\circ}$ during the first $\sim 40$ min of the event.

The existence of a BEES and AWFC was also clear in summary plots of backscatter power, or signal-to-noise ratio (SNR), and Doppler spectral width (neither shown). The scatter associated with the BEES and AWFC were characterised by strong SNR, 30-40 dB, and low spectral width, $<60 \mathrm{~m} \mathrm{~s}^{-1}$. This contrasts with the scatter found further poleward where the SNR was predominantly $<18 \mathrm{~dB}$ and the spectral width predominantly $>75 \mathrm{~m} \mathrm{~s}^{-1}$. This suggests the decametre-scale ionospheric irregularities associated with the BEES and AWFC were unusually intense (i.e. large $\delta n / n)$ and depending on the interpretation of the spectral widths, the irregularity coherence time was long, or the velocity turbulence was weak.

With reference to Fig. 1, there was a $\sim 126 \mathrm{nT}$ surge in the geomagnetic $X$ component during 07:01 to 07:57 UT (Fig. 1b), and there was an increase in energetic particle flux detected by LANL 1991-080 during 07:12 to 08:15 UT. The interval of DPP activity, 07:58 to 08:33 UT, may have produced fluctuations in the geomagnetic $X, Y$, and $Z$ components (Fig. 1b), as well as oscillation in the latitude of the BEES (Fig. 9). However, DPP effects are normally transient (Thorolfsson et al., 2001), and are not considered further in this study. The interpretation of the BEES amidst this complex sequence of events is an ongoing investigation.

The DMSP F13 satellite traversed the austral auroral oval from 21:36 to 19:36 MLT during 08:18 to 08:23 UT. The b2e boundary was located at $-64.6^{\circ}$ and 19:54 MLT, and the b1e boundary was located at $-62.7^{\circ}$ and 19:42 MLT. Referring to Figs. 9 and 10, the DMSP results suggest the BEES was expanding equatorward through the inner plasma sheet toward the plasmatrough. The WHISPER VLF observations (Fig. 3) suggest the separation between the auroral zone, as defined by auroral kilometric radiation and hiss, and the plasmapause was relatively small during this event.

Finally, the Iridium-based contours of FAC density for 09:30 UT (Fig. 7b) have been superimposed on the two summary plots. The contours were shifted by different amounts in time for the beam 0 and 15 summary plots because the eastern most beam 15 must have observed the same spatially stationary features at an earlier time. Obviously, translating a spatial pattern of FAC recorded at a fixed UT into the temporal variation observed on a fixed beam rotating in MLT is erroneous. However, to first order the dominate features in the FAC were stationary and sliding a 1-h accumulation window through the Iridium data base would produce artificial changes related to individual satellite passes entering and leaving the time window.

The Iridium results show that the BEES and AWFC were associated with the apparent equatorward movement of the Region 2 current, and the AWFC decayed when the Region 2 current was replaced by a weak upward current. Figure $7 \mathrm{e}$ confirms the Region 2 current was replaced by a weak upward current by $\sim 11: 00$ UT.

\subsection{Beam-swinging analysis}

The map potential analysis (Ruohoniemi and Baker, 1998) applies spatial and temporal median filtering to the $v_{\text {LOS }}$ values measured by all the radars to help achieve an accurate representation of large-scale ionospheric convection. However, the original beam-swinging technique described by Ruohoniemi et al. (1989) preserves more of the resolution of the radar measurements and is a useful tool for studying the smaller scale flows implied by the Doppler shifts measured by a single radar. Parkinson et al. (2003a) discuss how the beam-swinging analysis might underestimate the flow speeds, yet overestimate the flow channel width when it is not L-shell aligned.

Figure 10 represents the two-dimensional flow vectors estimated using the beam-swinging technique. Panels (a) and (b) plot the flow speeds and directions, respectively, against the magnetic latitude of TIGER beam 4, the magnetic meridian pointing beam. The time resolution is two minutes, or one vector per full scan, and the latitude resolution is $0.4^{\circ}$, corresponding to the $45-\mathrm{km}$ range resolution. A flow vector was calculated on every L shell when scatter was recorded on more than five beams and solutions consistent with a cosine fit were obtained. The flow speeds were colour coded using steps of $80 \mathrm{~m} \mathrm{~s}^{-1}$, with the largest speeds $\left(>720 \mathrm{~m} \mathrm{~s}^{-1}\right)$ highlighted in red. Similarly, the flow directions have been colour coded using steps of $18^{\circ}$ where azimuth $0^{\circ}$ is toward magnetic west.

The beam-swinging results have a noisy quality because the analysis is influenced by short-scale velocity fluctuations. However, the results show that the flow speeds poleward of $\sim-65^{\circ}$ were mostly strong and toward the 
west before $\sim 09: 35$ UT. Thereafter they were predominantly moderate, $<320 \mathrm{~m} \mathrm{~s}^{-1}$. However, several bursts of stronger anti-sunward flow commenced at latitudes poleward of $-75^{\circ}$ , the first starting at $\sim 09: 56$ UT. These flow bursts may have been the HF radar signatures of Bursty Bulk Flows (BBFs) (Angelopoulos et al., 1992; Grocott et al., 2004).

The large westward flows associated with the BEES expanded equatorward from $\sim-69^{\circ}$ at 07:03 UT. Although the BEES oscillated in latitude, it reached $-65^{\circ}$ at $\sim 08: 35 \mathrm{UT}$, and seemed to initiate the AWFC. The AWFC flows were especially strong, $>720 \mathrm{~m} \mathrm{~s}^{-1}$, within the latitude range $-62^{\circ}$ to $-64^{\circ}$ during $\sim 08: 46$ to 09:44 UT. They decayed to $<520 \mathrm{~m} \mathrm{~s}^{-1}$ after 10:42 UT, and to $<160 \mathrm{~m} \mathrm{~s}^{-1}$ by 13:08 UT.

IMAGE EUV plasmapause locations were identified once every $10 \mathrm{~min}$ at the magnetic longitude of TIGER beam 4 and were superimposed as bold, black triangles in Fig. 10. Plasmapause locations could not be identified at times earlier than shown because the drainage plume extended beyond the FoV of the EUV imager; nor at later times than shown because global-scale images were no longer available. The results show the equatorward edges of the BEES and AWFC were aligned with the plasmapause boundary as the radar FoV rotated in MLT. Recall from Fig. 6 that the drainage plume extended to greater radial distance (higher latitude) at earlier MLT.

Figure 10 also demonstrates that the TIGER radar observed a patch of ionospheric scatter which mapped to L shells within the outer plasmasphere. This "plasmaspheric scatter" was at the equatorward edge of the AWFC. Approaching magnetic midnight the plasmapause migrated equatorward of the region where TIGER observed F-region irregularities.

\section{Summary of results}

This study reports a comprehensive set of ground-based and satellite measurements to help provide insights into the relationship between the BEES, AWFC, plasmapause, and the Region 1 and 2 FACs, and other phenomena. We summarise the main results as follows:

1. The TIGER SuperDARN radar observed an AWFC during $\sim 08: 35$ to $13: 28$ UT in the dusk-to-midnight sector ( 19:00-23:00 MLT). A beam-swinging analysis provided estimates of the 2-D flows (Fig. 10). The AWFC flows were especially strong, $>720 \mathrm{~m} \mathrm{~s}^{-1}$, during 08:46 to 09:44 UT, and gradually decayed thereafter. The AWFC flows maximised in the magnetic latitude range $-62^{\circ}$ to $-64^{\circ}$, and were tilted slightly toward the pole at earlier MLT. Considerable structure existed within the AWFC, and it is likely larger velocities existed beneath the pixel size of the measurements (Parkinson et al., 2003a).
2. The TIGER radar observed a BEES during $~ 07: 03$ to 08:35 UT in the dusk sector ( 16:00-19:00 MLT on beam 4$)$. The BEES was associated with a strong poleward directed electric field concentrated within a narrow spatial region of $1-2^{\circ}$ (Fig. 9), and its equatorward expansion was contiguous with the start of the AWFC. The apparent overall equatorward movement of the BEES in UT was significantly faster than that of the Region 2 FAC and the adjacent plasmapause (Fig. 10). Hence the equatorward movement was partly caused by the radar rotating in MLT about a stationary plasma trough which was located at lower latitude at later MLT (Fig. 6). However, the more rapid displacements in latitude must have been caused by equatorward and poleward expansions related to ongoing substorm activity and the transient effects of the DPP (Fig. 1).

3. The AL index for 7 April 2001 indicates the observed AWFC was preceded by two large and distinct substorms (Substorm 1 and 2; Fig. 1a). These substorms had recovered prior to the AWFC. The MQI magnetometer observed a 250-nT positive deflection during 07:01 to 07:46 UT (Fig. 1b). The BEES commenced during this local Hall current intensification, but it continued beyond. The BEES was more coincident with LANL energetic particle activity measured at geosynchronous orbit. The AL index revealed the planetary conditions were moderately active $(\sim-200 \mathrm{nT})$ throughout the lifetime of the AWFC.

4. Cluster WHISPER-based identification of the plasmapause indicate it was stationary to within $\sim 1^{\circ}$ throughout the lifetime of the AWFC. The WHISPER and IMAGE EUV-based plasmapause locations indicate the peak AWFC flows were located $\sim 2^{\circ}$ poleward of the plasmapause. However, the equatorward edge of the weaker AWFC flows overlapped the plasmapause, and the TIGER radar observed ionospheric scatter on magnetic field lines which map to within the plasmasphere. More case studies may confirm that the equatorward limit of an AWFC defined by the equatorward edge of scatter combined with a velocity threshold is a reasonable proxy for plasmapause location.

5. The IMAGE EUV global-scale images of the plasmasphere (e.g., Fig. 6) showed that the AWFC mapped to the outer edge of the drainage plume plasmapause in the dusk-to-midnight sector. The drainage plume plasmapause was located at a greater $\mathrm{L}$ shell and became more diffuse at earlier MLT. Mapped to the ionosphere, this meant the plasmapause was located at a higher magnetic latitude at earlier MLT, similar to the poleward tilt of the AWFC. Goldstein et al. (2002, 2003, 2005) have demonstrated the importance of PJ/SAIDs in accounting for plasmapause erosion. 
6. Flow channels can be considered SAPS-related when they are located equatorward of the equatorward limit of significant fluxes $\left(>10^{6} \mathrm{~cm}^{-2} \mathrm{ster}^{-1} \mathrm{~s}^{-1}\right)$ of plasma sheet electrons precipitating with energy in the order of $1 \mathrm{keV}$ or more. Online DMSP SS J/4 observations of precipitating electrons (not shown) confirm that the peak of the AWFC was located equatorward of the inner edge of the plasma sheet. However, the poleward side of the AWFC overlapped the equatorward edge of electron precipitation, especially when the average electron energy decreased in the Earthward direction.

7. A DMSP F13 satellite pass during 10:03 to 10:07 UT revealed a nose of $\sim 10 \mathrm{keV}$ ion precipitation extending equatorward to $-63.6^{\circ}$. Spasojevic et al. (2004) reported IMAGE FUV observations of detached proton arcs mapping to the plasmasphere drainage plume and possibly caused by pitch angle scattering of RC ions by electromagnetic ion cyclotron waves.

8. The Iridium-based estimates of large-scale FAC show that the peak AWFC flows were collocated near to a peak Region 2 downward FAC in the dusk-to-midnight sector. The Region 1 upward FAC was located further poleward in the main electron auroral oval. Like the EUV plasmapause boundary, the peak Region 2 current receded to higher latitude at earlier MLT. The finite longitudinal extent of the Region 2 current suggests a relationship to partial RC closure. Within the 1-h time resolution of the FAC maps, the strength of the AWFC (Figs. 9 and 10) grew and decayed with the intensity of the afore-mentioned Region 1 and 2 currents (i.e., Fig. 7).

9. Application of Ampere's law to the Cluster FGM magnetic perturbations suggest the AWFC was coincident with a significant RC enhancement (Fig. 4). Moreover, derivatives of the FGM perturbations indicate that the AWFC mapped to the inner edge of intense filamentary current within the near-Earth plasma sheet (Fig. 5). Note that these high-altitude FACs were located above the auroral acceleration region and were probably different to the ionospheric FAC.

\section{Outstanding issues}

In the accepted picture for the formation and evolution of PJ/SAIDs (e.g., see Anderson et al., 1993; De Keyser, 1999; Parkinson et al., 2003a), a downward FAC enters the ionosphere in the region overlapping the equatorward side of the trough. Ionospheric current closure is in the form of a poleward Pedersen current across the main ionospheric trough. Current then leaves the ionosphere in the form of an upward FAC carried by precipitating electrons somewhere in the auroral region poleward of the trough. A poleward directed po- larisation electric field is focussed by electrodynamic feedback into the main trough because of its relatively low Pedersen conductivity. The poleward electric field grows and saturates non-linearly as ion neutral friction further reduces the plasma density and thus Pederson conductance within the main trough.

The AWFC studied here probably mapped to the location of the main ionospheric trough centred $\sim 2^{\circ}$ poleward of the plasmapause. This is because of the accepted association, albeit complicated, between the formation of the plasma trough and main ionospheric trough (Rodger and Pinnock, 1982; Yizengaw et al. 2005). The relatively weak Hall currents observed above MQI during the lifetime of the AWFC (Fig. 1b), an interval of strong ionospheric flow, suggests the ionospheric conductivity and thus plasma density were weak at this time.

Synchronicity between the intensity of the AWFC and the large-scale Region 1 and 2 dusk side currents (Fig. 7) suggests that the relevant current circuit was the downward Region 2 FAC, the poleward Pedersen current, and the upward Region 2 current. Closure via the zonal substorm current wedge and the meridional current system of Kamide et al. (1994) (see Grocott et al., 2006) may also have played a role. The current circuit may also have consisted of thin FAC sheets located immediately equatorward and poleward of the AWFC, but neither the Iridium or DMSP satellite observations revealed evidence for their existence.

Thin FAC structure might have been intense during the initial $\sim 10$ min of an AWFC, and thereafter almost disappeared because of the subsequent reduction of Pedersen conductance yet intensification of polarisation field across the trough. Although the DMSP magnetometer perturbations had sufficient time resolution to resolve thin FAC sheets, few coincident passes were available. Moreover, Iridium-based FAC maps were aliased at spatial scales less than $4^{\circ}$ in latitude, and thus thin FAC sheets separated by $\sim 2^{\circ}$, the width of the AWFC, might not be resolved. Small-scale FAC structure might be identified using fortuitous DMSP conjunctions, or by using the proposed upgrade of the Iridium-based FAC analysis to higher spatial $\left(\sim 0.25^{\circ}\right)$ and temporal $(\sim 9 \mathrm{~min})$ resolution.

What is the physical interpretation of the BEES? The available DMSP SS J/4 observations suggest the BEES mapped to a location in the near-Earth plasma sheet. IMAGE EUV data also suggests the BEES occurred deep inside the magnetosphere, just poleward of the plasma trough region (Fig. 10). The equatorward boundary of HF backscatter is known to expand equatorward during the growth phase of substorms (Yeoman et al., 1999), and the TIGER radar has frequently observed equatorward expansions of the HF backscatter during substorm growth and expansion phases (Parkinson et al., 2005b). However, the BEES consisted of a thin tendril of enhanced backscatter and poleward electric field contiguous with the AWFC. The characteristics of the BEES were more alike those of an AWFC, than the familiar 
growth phase signature observed in other events. Without corroborating evidence, we cannot conclude the BEES was a growth phase signature unrelated to AWFC formation.

Parkinson et al. (2002) reported TIGER observations of equatorward expanding regions of enhanced Doppler velocity which decayed across the HF radar spectral width boundary. These features were interpreted as the signatures of magnetic reconnection across the open-closed magnetic field line boundary. The corresponding 2-D flow vectors were predominantly equatorward and eastward in the midnight sector. Like the equatorward expanding regions of enhanced Doppler velocity shown in Fig. 10 of this paper, they may have been the ionospheric signatures of episodic BBFs (Angelopoulos et al., 1992; Grocott et al. 2004).

Figure $7 \mathrm{~b}$ of Parkinson et al. (2005a) showed a succession of BEES-like features expanding equatorward into the region of an AWFC in the pre-midnight sector. These features represent the equatorward expansion of enhanced poleward electric field through the inner plasma sheet. They may also have been related to BBFs, but their continuity with the AWFC suggests another aspect of their evolution. The BEES reported in this paper was observed in the dusk sector, and its continuity in time and latitude is inconsistent with our understanding of magnetic reconnection. It seems reasonable to conjecture the BEES represents some unexplained process feeding the AWFC region.

Parkinson et al. (2003a, 2005a) reported AWFCs that were synchronised with distinct substorms, yet the present AWFC was observed during $\sim 08: 35$ to 13:28 UT, well after Substorms 1 and 2. Although the AL index showed sustained moderate activity $(\sim-200 \mathrm{nT})$ throughout the lifetime of the AWFC, the MQI magnetometer did not reveal evidence for a distinct intensification or substorm synchronised with the AWFC. In this respect, the present AWFC may have been different to the previously reported events. There is a possibility that AWFCs will be observed during geomagnetic quiet conditions.

Development of the RC and FAC, and any other conditions required for the generation of an AWFC, may have been established during the preceding substorms. Although the global substorm cycle lasts $1-2 \mathrm{~h}$, the resulting energisation of the radiation belt and RC persists on longer time scales, as confirmed by subsequent evolution of the $D_{s t}$ index (Fig. 1a). Figure 1b also shows the LANL satellites detected an extended interval of energetic particle flux activity immediately preceding the AWFC. There is a possibility the AWFC development was related to prior magnetospheric activity.

The results of this study indicate that our understanding of the inter-relationship between AWFCs and the zoo of nightside phenomena and their ultimate role in cross-scale coupling is far from complete. The present results show that BEES are long-lived and spatially localised electric field enhancements occurring within the dusk sector of the nearEarth plasma sheet, and they are related in some way to
AWFC dynamics. The correct physical interpretation of BEES will require analysis of new data sets with better continuity and resolution in time and space. Clearly, the development and evolution of the BEES and an AWFC needs to be modelled in the context of radiation belt, RC, and FAC development driven by substorm current disruption, reconnection, and particle injection.

Acknowledgements. This work was supported by the Australian Research Council, the Australian Antarctic Science Advisory Council, the Australian Academy of Sciences, and the TIGER Consortium Partners (La Trobe University, Australian Antarctic Division, DSTO Intelligence Surveillance and Reconnaissance Division, IPS Radio and Space Services, Monash University, University of Newcastle). The World Data Centre for Geomagnetism, Kyoto, Japan is thanked for providing $\mathrm{AU}$ and $\mathrm{AL}$ indices. Geosciences Australia are thanked for providing MQI magnetometer data. N. CornilleauWehrlin is thanked for providing Cluster STAFF measurements and $\mathrm{H}$. Rème is thanked for providing Cluster CIS measurements. B. R. Sandel is thanked for providing the IMAGE EUV data. The DMSP particle detectors were designed by D. Hardy of AFRL, and data were obtained from JHU/APL. We thank D. Hardy, F. Rich, and P. Newell for its use. M. Hairston at the Center for Space Sciences at the University of Texas at Dallas is thanked for providing SSIES data. M. Lester was supported by PPARC grant PPA/G/O/2003/00013. Finally, we thank H. Ye, M. Gentile, J. Devlin, P. Dyson, and numerous other people who contributed to the operation of TIGER.

Topical Editor M. Pinnock thanks T. Kikuchi and another referee for their help in evaluating this paper.

\section{References}

Anderson, P. C., Hanson,W. B., Heelis, R. A., Craven, J. D., Baker, D. N., and Frank, L. A.: A proposed production model of rapid subauroral ion drifts and their relationship to substorm evolution, J. Geophys. Res., 98, 6069-6078, 1993.

Angelopoulos, V., Baumjohann, W., Kennel, C. F., Coroniti, F. V., Kivelson, M. G., Pellat, R., Walker, R. J., Lühr, H., and Paschmann, G.: Bursty bulk flows in the central plasma sheet, J. Geophys. Res., 97, 4027-4039, 1992.

Baker, K. B. and Wing, S.: A new magnetic coordinate system for conjugate studies of high latitudes, J. Geophys. Res., 94, 91399143, 1989.

Balogh, A., Dunlop, M. W., Cowley, S. W. H., Southwood, D. J., Thomlinson, J. G., Glassmeier, K.-H., Musmann, G., Luhr, H., Buchert, S., Acuna, M., Fairfield, D. H., Slavin, J. A., Riedler, W., Schwingenschuh, K., and Kivelson, M. G.: The Cluster magnetic field investigation, Space Sci. Rev., 79, 65-91, 1997.

Balogh, A., Carr, C. M., Acuña, M. H., Dunlop, M. W., Beek, T. J., Brown, P., Fornacon, K.-H., Georgescu, E., Glassmeier, K.H., Harris, J., Musmann, G., Oddy, T., and Schwingenschuh, K.: The Cluster Magnetic Field Investigation: Overview of in-flight performance and initial results, Ann. Geophys., 19, 1207-1217, 2001, http://www.ann-geophys.net/19/1207/2001/.

Burke, W. J., Maynard, N. C., Hagan, M. P., Wolf, R. A., Wilson, G. R., Gentile, L. C., Gussenhoven, M. S., Huang, C. Y., Garner, 
T. W., and Rich, F. J.: Electrodynamics of the inner magnetosphere observed in the dusk sector by CRRES and DMSP during the magnetic storm of June 4-6, 1991, J. Geophys. Res., 103, 29399-29418, 1998.

Canu, P., Décréau, P. M. E., Trotignon, J. G., Rauch, J. L., Séran, H. C., Fergeau, P., Lévêque, M., Martin, Ph., Sené, F. X., Le Guirriec, E., Alleyne, H., and Yearby, K.: Identification of natural plasma emissions with the Cluster - Whisper relaxation sounder, Ann. Geophys., 19, 1697-1709, 2001,

http://www.ann-geophys.net/19/1697/2001/.

Cornilleau-Wehrlin, N., Chauveau, P., Louis, S., Meyer, A., Nappa, J. M., Perraut, S., Rezeau, L., Robert, P., Roux, A., de Villedary, C., de Conchy, Y., Friel, L., Harvey, C. C., Hubert, D., Lacombe, C., Manning, R., Wouters, F., Lefeuvre, F., Parrot, M., Pinçon, J. L., Poirier, B., Kofman, W., and Louarn, P.: The Cluster SpatioTemporal Analysis of Field Fluctuations (STAFF) Experiment, Space Sci. Rev., 79, 107-136, 1997.

Décréau, P. M. E., Fergeau, P., Lévêque, M., Martin, Ph., Randriamboarison, O., Sené, F. X., Trotignon, J. G., Canu, P., de Féraudy, H., Bahnsen, A., Jespersen, M., Mögensen, P. B., Iversen, I., Dunford, C., Sumner, A., Woolliscroft, L. J. C., Gustafsson, G., and Gurnett, D. A.: "Whisper", a sounder and High frequency wave analyser experiment, ESA SP-1159, 5167, 1993.

Décréau, P. M. E., Fergeau, P., Krasnoselskikh, V., Lévêque, M., Martin, Ph., Randriamboarison, O., Sené, F. X., Trotignon, J. G., Canu, P., Mögensen, P. B. and Whisper investigators: Whisper, a resonance sounder and wave analyser: performances and perspectives for the Cluster mission, Space Sci. Rev., 79, 93-105, 1997.

De Keyser, J.: Formation and evolution of subauroral ion drifts in the course of a substorm, J. Geophys. Res., 104, 12 339-12 349, 1999.

Dyson, P. L. and Devlin, J. C.: The Tasman International Geospace Environment Radar, The Physicist (The Australian Institute of Physics), 37, 48-53, March/April 2000.

Dyson, P. L., Devlin, J. C., Parkinson, M. L., and Whittington, J. S.: The Tasman International Geospace Environment Radar (TIGER)-Current Development and Future Plans, IEEE Proceedings of the International Conference on Radar, IEEE Catalogue No. 03EX695C, 282-287, 2003.

Dyson, P. L., Parkinson, M. L., Conde, M., and Devlin, J. C.: New investigations in magnetosphere-ionosphere-thermosphere processes and their impact on space weather, Proceedings, NSSA Space Science Conference, Melbourne, 13-15 September 2005.

Escoubet, C. P., Fehringer, M., and Goldstein, M.: The Cluster Mission, Ann. Geophys., 19, 1197-1200, 2001,

http://www.ann-geophys.net/19/1197/2001/.

Fejer, B. G.: The electrodynamics of the low-latitude ionosphere: recent results and future challenges, J. Atmos. Solar-Terr. Phys., 59, 1465-1482, 1997.

Foster, J. C. and Burke, W. J.: SAPS, A new categorization for subauroral electric fields, EOS, Tranactions, American Geophysical Union, 83(36), 393-394, 2002.

Freeman, M. P., Southwood, D. J., Lester, M., Yeoman, T. K., and Reeves, G. D.: Substorm-associated radar auroral surges, J. Geophys. Res., 97, 12 173-12 185, 1992.

Galperin, Y. I., Ponomarev, V. N., and Zosimova, A. G.: Direct measurements of ion drift velocity in the upper ionosphere during a magnetic storm, 2. Results of measurements during the November 3, 1967, magnetic storm, Cosmic Res. (Russian), 11, 283 292, 1973.

Goldstein, J., Burch, J. L., and Sandel, B. R.: Magnetospheric model of subauroral polarization stream. J. Geophys. Res., 110, A09222, doi:10.1029/2005JA011135, 2005.

Goldstein, J., Sandel, B. R., Hairston, M. R., and Reiff, P. H.: Control of plasmaspheric dynamics by both convection and subauroral polarization stream, Geophys. Res. Lett., 30(24), 2243 , doi:10.1029/2003GL018390, 2003

Goldstein, J., Burch, J. L., Sandel, B. R., Mende, S. B., Brandt, R. C., and Hairston, M. R.: Coupled response of the inner magnetosphere and ionosphere on 17 April 2002, J. Geophys. Res., 110, A03205, doi:10.1029/2004JA010712, 2005.

Greenwald, R. A., Baker, K. B., Hutchins, R. A., and Hanuise, C.: An HF phased-array radar for studying small-scale structure in the high-latitude ionosphere, Radio Sci., 20, 63-79, 1985.

Greenwald, R. A., Baker, K. B., Dudeney, J. R., et al.: DARN/SuperDARN: A global view of the dynamics of highlatitude convection, Space Sci. Rev., 71, 761-796, 1995.

Grocott, A., Yeoman, T. K., Nakamura, R., Cowley, S. W. H., Rème, H., and Klecker, B.: Multi-instrument observations of the ionospheric counterpart to a bursty bulk flow in the near-Earth plasma sheet, Ann. Geophys., 22, 1061-1075, 2004, http://www.ann-geophys.net/22/1061/2004/.

Grocott, A., Lester, M., Parkinson, M. L., Yeoman, T. K., Dyson, P. L., Devlin, J. C., and Frey, H. U.: Towards a synthesis of substorm electrodynamics: HF radar and auroral observations, Ann. Geophys., 24, 3365-3381, 2006, http://www.ann-geophys.net/24/3365/2006/.

Horvath, I. and Essex, E. A.: Using observations from the GPS and TOPEX satellites to investigate night-time TEC enhancements at mid-latitudes in the southern hemisphere during a low sunspot number period, J. Atmos. Solar-Terr. Phys., 62, 371-391, 2000.

Huang, C.-S., Foster, J. C., and Holt, J. M.: Westward plasma drift in the midlatitude ionospheric F region in the midnight-dawn sector, J. Geophys. Res., 106, 30 349-30 362, 2001.

Iijima, T. and Potemra, T. A.: Large-scale characteristics of fieldaligned currents associated with substorms, J. Geophys. Res., 83, 599-615, 1978.

Kamide, Y., Richmond, A. D., Emery, B. A., et al.: Ground-based studies of ionospheric convection associated with substorm expansion, J. Geophys. Res., 99, 19451-19466, 1998.

Karlsson, T., Marklund, G. T., and Blomberg, L. G.: Subauroral electric fields observed by the Freja satellite: A statistical study, J. Geophys. Res., 103, 4327-4341, 1998.

Kelley, M. C., Fejer, B. G., and Gonzales, C. A.: An explanation for anomalous equatorial ionospheric electric fields associated with a northward turning of the interplanetary magnetic field, Geophys. Res. Lett., 6, 301-304, 1979.

Khan, H. and Cowley, S. W. H.: Observations of the response time of high-latitude ionospheric convection to variations in the interplanetary magnetic field using EISCAT and IMP-8 data, Ann. Geophys., 17, 1306-1355, 1999, http://www.ann-geophys.net/17/1306/1999/.

Lui, A. T. Y.: Multiscale phenomena in the near-Earth magnetosphere, J. Atmos. Solar-Terr. Phys., 64, 125-143, 2002.

McComas, D. J., Bame, S. J., Barker, P., Feldman, W. C., Phillips, J. L., Riley, P., and Griffee, J. W.: Solar Wind Electron Proton 
Alpha Monitor (SWEPAM) for the Advanced Composition Explorer, Space Sci. Rev., 86, 563-612, 1998.

Mende, S. B., Heetderks, H., Frey, H. U., Lampton, M., Geller, S. P., Habraken, S., Renotte, E., Jamar, C., Rochus, P., Spann, J., Fuselier, S. A., Gerard, J.-C., Gladstone, R., Murphree, S., and Cogger, L.: Far ultraviolet imaging from the IMAGE spacecraft. 1. System design, Space Sci. Rev., 91, 243-270, 2000 a.

Mende, S. B., Heetderks, H., Frey, H. U., Lampton, M., Geller, S. P., Abiad, R., Segmund, O. H. W., Tremsin, A. S., Span, J., Dougani, H., Fuselier, S. A., Magoncelli, A. L., Bumala, M. B., Murphree, S., and Trondsen, T.: Far ultraviolet imaging from the IMAGE spacecraft. 2. Wideband FUV imaging, Space Sci. Rev., 91, 271-285, 2000b.

Milan, S. E., Sato, N., Lester, M., Murata, Y., Shinkai, Y., Doi, H., Frey, H. U., and Saemundsson, T.: E-region echo characteristics governed by auroral arc electrodynamics, Ann. Geophys., 21, 1567-1575, 2003, http://www.ann-geophys.net/21/1567/2003/.

Parkinson, M. L., Polglase, R., Fejer, B. G., Scherliess, L., Dyson, P. L., and Ujmaia, S. M.: Seasonal and magnetic activity variations of ionospheric electric fields above the southern mid-latitude station, Bundoora, Australia, Ann. Geophys., 19, 521-532, 2001, http://www.ann-geophys.net/19/521/2001/.

Parkinson, M. L., Pinnock, M., Ye, H., Hairston, M. R., Devlin, J. C., Dyson, P. L., Morris, R. J., and Ponomarenko, P.: On the lifetime and extent of an auroral westward flow channel (AWFC) observed during a magnetospheric substorm, Ann. Geophys., 21, 893-913, 2003a.

Parkinson, M. L., Devlin, J. C., Ye, H., Waters, C. L., Dyson, P. L., Breed, A. M., and Morris, R. J.: On the occurrence and motion of decametre-scale irregularities in the sub-auroral, auroral, and polar cap ionosphere, Ann. Geophys., 21, 1847-1868, 2003 b.

Parkinson, M. L., Pinnock, M., Wild, J. A., Lester, M., Yeoman, T. K., Milan, S. E., Ye, H., Devlin, J. C., Frey, H. U., and Kikuchi, T.: Interhemispheric asymmetries in the occurrence of magnetically conjugate sub-auroral polarisation streams, Ann. Geophys., 23, 1371-1390, 2005a.

Parkinson, M. L., Pinnock, M., Dyson, P. L., and Devlin, J. C.: Signatures of the nightside open-closed magnetic fieldline boundary during moderately disturbed conditions and ionospheric substorms, Adv. Space Res., 36, 1791-1796, doi:10.1016/j.asr.2005.06.082, 2005b.

Parkinson, M. L., Dyson, P. L., and Pinnock, M.: On the occurrence of auroral westward flow channels and substorm phase, Adv. Space Res., 38(8), 1755-1762, doi:10.1016/j.asr.2005.08.028, 2006.

Rème, H., Cottin, F., Cros, A., et al.: The Cluster Ion Spectrometry (CIS) Experiment, Space Sci. Rev., 79, 303-350, 1997.

Rème, H., Aoustin, C., Bosqued, J., Dandouras, I., Lavraud, B., Sauvaud, J. A., Barthe, A., Bouyssou, J., Camus, Th., CoeurJoly, O., et al.: First multispacecraft ion measurements in and near the Earth's magnetosphere with the identical Cluster ion spectrometry (CIS) experiment, Ann. Geophys., 19, 1303-1354, 2001 , http://www.ann-geophys.net/19/1303/2001/.

Rodger, A. S., Moffett, R. J., and Quegan, S.: The role of ion drift in the formation of ionisation troughs in the mid- and high-latitude ionosphere - a review, J. Atmos. Terr. Phys., 54, 1-30, 1992.

Ruohoniemi, J. M., Greenwald, R. A., Baker, K. B., Villain, J.-P.,
Hanuise, C., and Kelly, J.: Mapping high-latitude plasma convection with coherent HF radars, J. Geophys. Res., 94, $13463-$ 13 477, 1989.

Ruohoniemi, J. M. and Greenwald, R. A.: Statistical patterns of high-latitude convection obtained from Goose Bay HF radar observations, J. Geophys. Res., 101, 21 743-21 763, 1996.

Ruohoniemi, J. M. and Baker, K. B.: Large-scale imaging of highlatitude convection with Super Dual Auroral Radar Network HF radar observations, J. Geophys. Res., 103, 20 797-20 811, 1998.

Sandel, B. R., Broadfoot, A. L., Curtis, C. C., King, R. A., Stone, T. C., Hill, R. H., Chen J., Siegmund, O. H. W., Raffanti, R., Allred, D., Turley, S., and Gallagher, D. I.: The Extreme Ultraviolet Imager investigation for the IMAGE mission, Space Sci. Rev., 91, 197-242, 2000.

Sandel B. R., King, R. A., Forrester, W. T., Gallagher, D. L., Broadfoot, A. L., and Curtis, C. C.: Initial results from the IMAGE Extreme Ultraviolet Imager, Geophys. Res. Lett., 28, 1439-1442, 2001.

Shand, B. A., Lester, M., and Yeoman, T. K.: Substorm associated radar auroral surges: a statistical study and a possible generation model, Ann. Geophys., 16, 441-449, 1998, http://www.ann-geophys.net/16/441/1998/.

Smith, C. W., L'Heureux, J., Ness, N. F., Acuna, M. H., Burlaga, L. F., and Scheifele, J.: The ACE magnetic fields experiment, Space Sci. Rev., 86, 613-632, 1998.

Spasojevic, M., Frey, H. U., Thomsen, M. F., Fuselier, S. A., Gary, S. P., Sandel, B. R., and Inan, U. S.: The link between a detached subauroral proton arc and a plasmaspheric plume, Geophys. Res. Lett., 31, L04803, doi:10.1029/2003GL018389, 2004.

Spiro, R. W., Heelis, R. A., and Hanson, W. B.: Rapid subauroral ion drifts observed by Atmospheric Explorer C, Geophys. Res. Lett., 6, 660-663, 1979.

Thorolfsson, A., Cerisier, J.-C., and Pinnock, M.: Flow transients in the postnoon ionosphere: The role of solar wind dynamic pressure, J. Geophys. Res., 106, 1887-1901, 2001.

Trotignon J. G., Décréau, P. M. E., Rauch, J. L., Randriamboarison, O., Krasnoselskikh, V., Canu, P., Alleyne, H., Yeraby, K., Le Guirriec, E., Séran, H. C., Sené, F. X., Martin, Ph., Lévêque, M., and Fergeau, P.: How to determine the thermal electron density and the magnetic field strength from the CLUSTER/WHISPER observations around the Earth, Ann. Geophys., 19, 1711-1720, 2001,

http://www.ann-geophys.net/19/1711/2001/.

Tsyganenko, N. A.: Modeling the Earth's magnetospheric magnetic field confined within a realistic magnetopause, J. Geophys. Res., 100, 5599-5612, 1995.

Tsyganenko, N. A. and Stern, D. P.: Modeling the global magnetic field of the large-scale Birkeland current systems, J. Geophys. Res., 101, 27 187-27 198, 1996.

Vallat, C., Dandouras, I., Dunlop, M., Balogh, A., Lucek, E., Parks, G. K., Wilber, M., Roelof, E. C., Chanteur, G., and Rème, H.: First current density measurements in the ring current region using simultaneous multi-spacecraft CLUSTER-FGM data, Ann. Geophys., 23, 1849-1865, 2005, http://www.ann-geophys.net/23/1849/2005/.

Villain, J. P., Caudal, G., and Hanuise, C.: A SAFARI-EISCAT comparison between the velocity of $F$ region small-scale irregularities and ion drift, J. Geophys. Res., 90, 8433-8444, 1985.

Waters, C. L., Anderson, B. J., and Liou, K.: Estimation of global 
field aligned currents using the Iridium ${ }^{\circledR}$ system magnetometer data, Geophys. Res. Lett., 28, 2165-2168, 2001.

Waters, C. L., Anderson, B. J., Greenwald, R. A., Barnes, R. J., and Ruohoniemi, J. M.: High-latitude poynting flux from combined Iridium and SuperDARN data, Ann. Geophys., 22, 2861-2875, 2004,

http://www.ann-geophys.net/22/2861/2004/.

Wygant, J., Rowland, D., Singer, H. J., Temerin, M., Mozer, F., and Hudson, M. K., Experimental evidence on the role of the large spatial scale electric field in creating the ring current, J. Geophys. Res., 103, 29 527-29 544, 1998.
Yeoman, T. K., Lewis, R. V., Milan, S. E., Watanabe, M.: An interhemispheric study of the ground magnetic and ionospheric electric fields during the substorm growth phase and expansion phase onset, J. Geophys. Res., 104, 14 867-14 877, 1999.

Yeoman, T. K., Wright, D. M., Stocker, A. J., and Jones, T. B.: An evaluation of range accuracy in Super Dual Auroral Radar overthe-horizon HF radar systems, Radio Sci., 36, 801-813, 2001. 